University of New Hampshire

University of New Hampshire Scholars' Repository

$11-2003$

\title{
Remote sensing of sediment characteristics by optimized echo- envelope matching
}

\author{
Daniel D. Sternlicht \\ University of California - San Diego \\ Christian de Moustier \\ University of California - San Diego
}

Follow this and additional works at: https://scholars.unh.edu/ccom

Part of the Oceanography and Atmospheric Sciences and Meteorology Commons

\section{Recommended Citation}

D. D. Sternlicht and C. P. de Moustier, 'Remote sensing of sediment characteristics by optimized echoenvelope matching', The Journal of the Acoustical Society of America, vol. 114, no. 5, p. 2727, 2003.

This Journal Article is brought to you for free and open access by the Center for Coastal and Ocean Mapping at University of New Hampshire Scholars' Repository. It has been accepted for inclusion in Center for Coastal and Ocean Mapping by an authorized administrator of University of New Hampshire Scholars' Repository. For more information, please contact Scholarly.Communication@unh.edu. 


\title{
Remote sensing of sediment characteristics by optimized echo-envelope matching ${ }^{\text {a) }}$
}

\author{
Daniel D. Sternlicht ${ }^{\text {b) }}$ and Christian P. de Moustier ${ }^{\mathrm{c})}$ \\ Marine Physical Laboratory, Scripps Institution of Oceanography, University of California at San Diego, \\ La Jolla, California 92093-0205
}

(Received 1 November 1999; revised 13 June 2003; accepted 26 June 2003)

\begin{abstract}
A sediment geoacoustic parameter estimation technique is described which compares bottom returns, measured by a calibrated monostatic sonar oriented within $15^{\circ}$ of vertical and having a $10^{\circ}-21^{\circ}$ beamwidth, with an echo envelope model based on high-frequency $(10-100 \mathrm{kHz})$ incoherent backscatter theory and sediment properties such as: mean grain size, strength, and exponent of the power law characterizing the interface roughness energy density spectrum, and volume scattering coefficient. An average echo envelope matching procedure iterates on the reflection coefficient to match the peak echo amplitude and separate coarse from fine-grain sediments, followed by a global optimization using a combination of simulated annealing and downhill simplex searches over mean grain size, interface roughness spectral strength, and sediment volume scattering coefficient. Error analyses using Monte Carlo simulations validate this optimization procedure. Moderate frequencies $(33 \mathrm{kHz})$ and orientations normal with the interface are best suited for this application. Distinction between sands and fine-grain sediments is demonstrated based on acoustic estimation of mean grain size alone. The creation of feature vectors from estimates of mean grain size and interface roughness spectral strength shows promise for intraclass separation of silt and clay. The correlation between estimated parameters is consistent with what is observed in situ. (C) 2003 Acoustical Society of America. [DOI: 10.1121/1.1608019]
\end{abstract}

PACS numbers: 43.30.Gv, 43.30.Hw, 43.30.Ft, 43.30.Pc [DLB] Pages: 2727-2743

\section{INTRODUCTION}

Remote classification of ocean sediments is motivated by mineral resources assessment, cable and pipeline route planning, and mine warfare. In recent years a number of high-frequency $(>10 \mathrm{kHz})$ echo analysis techniques have been developed for characterizing the upper layer of seafloor sediments.

Sediment classification techniques using single-beam sonars are either phenomenological or physical. Phenomenological approaches identify nonparametric measured echo characteristics with core samples or bottom photographs. Such systems typically require calibration of signal characteristics with ground truth at the beginning of each survey, and operation must proceed at a fixed sensor altitude. Pace and Ceen investigated sediment characterization using single-beam echoes, ${ }^{1}$ where comparison of the expanded echo (due to temporal spreading) with the transmit pulse was used to infer bottom roughness. Echo durations commensurate with the duration of the transmit pulse were thought to originate from smooth substrates, whereas longer, variably shaped echoes were attributed to coarse materials. Sediment classification techniques that empirically match echo characteristics to ground truth have since been developed. One such system $^{2}$ exploits the bottom echo and the first surface multiple (bottom-surface-bottom) by integrating the energy

\footnotetext{
a) Parts of this manuscript were presented in the talks: Sternlicht and de Moustier [J. Acoust. Soc. Am. 105, 1206 (1999)] and Sternlicht and de Moustier [J. Acoust. Soc. Am. 108, 2536 (2000)].

${ }^{b}$ Current address: Dynamics Technology Inc., 21311 Hawthorne Blvd., Suite 300, Torrance, CA 90503. Electronic mail: dsternlicht@ dynatec.com c) Current address: Center for Coastal and Ocean Mapping, University of New Hampshire, 24 Colovos Road, Durham, NH 03824. Electronic mail: cpm@ccom.unh.edu
}

over the tail section of the first return, and integrating over the entire length of the multiple. Representation of these two measures as feature vectors allows segregation of a variety of bottom types. Building on this paradigm, multifeature classification techniques based on higher moment statistics of the recorded waveform are being investigated. ${ }^{3,4}$

Results from Ref. 1 inspired interpretation of the bottom echo's tail as an indicator of bottom roughness, while the energy content of the multiple is considered an indicator of the reflection coefficient, or hardness of the substrate. Theoretical explanations for the success of these systems and modeling of the bistatic geometry are being investigated. ${ }^{5,6}$

In physics-based approaches, sediment characteristics are estimated by comparing measurements to predictions made with physical models-thus minimizing presurvey training requirements and removing limitations on sensor altitude that, typically, are found in phenomenological approaches. One example of physics-based acoustic sediment characterization is described in the works of Schock, LeBlanc, and Mayer, ${ }^{7,8}$ wherein broadband $(2-10 \mathrm{kHz})$ echo amplitudes are used to estimate coherent reflection coefficients of sediment layers, and measured distortions of echo spectra yield information on sediment attenuation properties.

The inspiration for our work comes from physics-based echo envelope inversion techniques described by Berry, ${ }^{9}$ Nesbitt, ${ }^{10}$ Jackson and Nesbitt, ${ }^{11}$ and Lurton and Pouliquen. ${ }^{12}$ Berry's estimation of irradiated surface characteristics employs half-power lengths of measured and modeled average radar backscatter envelopes. Nesbitt used a least-squares search for matching acoustic backscatter envelopes with models based on reflection loss, sediment absorption coefficient, rms bottom slope, and a sediment volume scattering parameter. His work incorporated up to two sedi- 
coustic backscatter models for extracting bottom character istics from single-beam echo-sounder data. Lurton and Pouliquen described a method for sea-bottom identification comparing normalized cumulative functions of the echo envelope derived from measurements and physical backscatter models. Waveform normalization allows for the use of uncalibrated echo-sounders; however, ignoring echo strength limits exploitation of important information such as impedance contrast at the water-sediment interface. Furthermore, integration of echo envelope time series into cumulative form disproportionately represents signal components occurring earlier in time (closer to normal incidence).

In this work, we match a physics-based echo intensity envelope model ${ }^{13}$ to seafloor acoustic backscatter measurements, made over substrates ranging from clay to sand, collected with calibrated 33- and $93-\mathrm{kHz}$ echo-sounders whose 3 - $\mathrm{dB}$ beamwidths $\left(10^{\circ}-21^{\circ}\right)$ and elevation angles (maximum response axis at $0^{\circ}-15^{\circ}$ incidence) are consistent with the model's underlying Kirchhoff scattering theory. This model incorporates the system's deployment geometry, beam pattern, and signal characteristics, the ocean volume spreading and absorption losses, and solutions of the monochromatic wave equation using boundary conditions described by the sediment geoacoustic characteristics. The time-dependent intensity measured at the transducer face $I(t)$ is modeled as the sum of a sediment interface component $I_{i}(t)$ and a sediment volume component $I_{v}(t)$

$$
I(t)=I_{i}(t)+I_{v}(t),
$$

where, following the theoretical work of Jackson et al. ${ }^{14}$ the interface backscatter component is obtained from a solution of the Helmholtz diffraction integral using the Kirchhoff approximation, and a composite roughness approach is used to predict scattering from the sediment volume.

Model parameters include the mean grain size $\left(M_{\phi}\right)$, defined as $M_{\phi}=-\log _{2} D_{g}$, where $D_{g}$ is the sediment's mean grain diameter, ${ }^{15,16}$ and its correlates, the sediment:water density and sound-speed ratios $(\rho, \nu)$, and the sediment's compressional wave attenuation constant $\left(\kappa_{p}\right.$ in $\mathrm{dB} / \mathrm{m} / \mathrm{kHz}) .{ }^{17}$ Fluctuations of these properties are incorporated into a sediment scattering coefficient, $\sigma_{v}\left(\mathrm{~m}^{-1}\right)$, signifying the scattering cross section per unit volume, per unit solid angle. The interface is modeled by a power-law relief energy density spectrum $W(\mathbf{k})=w_{2} k^{-\gamma}$, where $\mathbf{k}$ is the bottom relief's two-dimensional wave number vector with magnitude $k, w_{2}$ is the spectral strength (expressed in units $\mathrm{cm}^{4}$ ), and $\gamma$ is the spectral exponent. The roughness spectrum is bandlimited to wave numbers spanning approximately an order of magnitude above and below the acoustic wave number.

The expected in situ ranges of the model components are: $\quad-1 \leqslant M_{\phi} \leqslant 9,2.4 \leqslant \gamma \leqslant 3.9,0.0 \leqslant w_{2} \leqslant 1.0,0.8 \leqslant \nu$ $\leqslant 3.0,1.0 \leqslant \rho \leqslant 3.0,0.01 \leqslant \kappa_{p} \leqslant 1,0.0 \leqslant \sigma_{v} \leqslant 1.0 \alpha_{b} . \alpha_{b}$ is the sediment compressional wave attenuation coefficient in $\mathrm{dB} / \mathrm{m}$, calculated as $\alpha_{b}=\kappa_{p} \times f_{a},{ }^{18}$ and $f_{a}$ is the acoustic frequency in $\mathrm{kHz}$. If the statistics describing the sediment characteristics are consistent over measurement scales commensurate with the geographic range of collected bottom echoes, the geoacoustic parameters described above may be estimated from optimized comparisons of the echo envelope model with aligned and averaged data.

Normalized angular dependence curves of seafloor acoustic backscatter, measured with the 16-beam SeaBeam echo-sounder, fitted with computed curves parametrized by the relief spectrum components $\left(\gamma, w_{2}\right)$ was presented by Michalopoulou et al. ${ }^{19}$ Using a least-squares maximum likelihood estimator and chi-square acoustic backscatter intensity statistics, the potential of matching acoustic backscatter models with statistically independent measurements was demonstrated. A drawback of this implementation is its reliance on exhaustive search procedures and its limitation to high-impedance contrast, impenetrable substrates with no demonstrable volume component. Another approach is described in Matsumoto et al. ${ }^{20}$ where global optimization by simulated annealing and downhill simplex is used to estimate relief spectrum parameters from the same kind of SeaBeam acoustic data.

The samples of the time series measured with a single echo-sounder are partially correlated, making the statistical approach of Ref. 19 inappropriate. Instead, the model's pressure time series are matched to measured echo envelopes calculated from stacked and averaged data with a two-stage, average echo envelope matching procedure, which builds on the work of Matsumoto et al..$^{20}$ by expanding the optimization to include relief spectrum parameters and physical quantities related to grain size and sediment volume scattering.

By incorporation of the measurement system's transmit and receive sensitivities, directional characteristics, and a filtering operation for converting voltage waveforms measured at the transducer terminals to pressure waveforms incident at the transducer, ${ }^{21}$ the shape and amplitude of the bottom's angular response is exploited in a model-data matching scheme appropriate for simple, inexpensive, single-beam echo sounders. This is distinguished from other physicsbased approaches which compare normalized measurements of uncalibrated returns to normalized model realizations, ${ }^{12}$ and from phenomenological seafloor characterization techniques $^{2,4}$ using correlation analysis of measured echo features (e.g., amplitude and energy in bottom echoes and respective surface multiples) with known ground truth.

Our physics-based model-data optimization procedure generates feature vectors with elements consisting of quantifiable geoacoustic parameters $\left(M_{\phi}, w_{2}, \sigma_{v}\right)$. This information can be directly associated with bottom type; thus, the procedure is, in theory, independent of specific site characteristics or insonification geometry (such as water depth or transducer orientation). In addition, the sensitivity of this optimization procedure to echo variability can be estimated from the covariance matrix of geoacoustic features, derived from synthetic data sets generated with the data covariance matrix for an ensemble of returns. Furthermore, correlation between the geoacoustic parameters (whether due to natural phenomena or artifacts of the optimization procedure) can be characterized.

Computation of the average echo envelope from data, and of a signal to error ratio in the model-data fit are described in Sec. II, with an example of the data covariance matrix and its implications to the model-data matching pro cedure. The two-stage model-data optimization procedure 
for estimating bottom characteristics is presented in Sec. III, with a method of evaluating the error propagation inherent to the matching procedure, using parameter covariance matrices produced from Monte Carlo simulated data sets. The system and data used to validate the echo envelope model and parameter estimation technique are described in Sec. IV, with results presented in Sec. V, and analyses of the effects of echo variability on the optimization procedure given in Sec. VI. Section VII draws conclusions about the usefulness and shortcomings of the approach, and its potential for seafloor classification.

\section{AVERAGE ECHO ENVELOPE}

The measured bottom echo consists of a pulsed CW signal, modulated by the bottom backscattering process, whose envelope detection and sampling at period $\tau_{e}$ yield an rms pressure sequence, $p[n]$, expressed in units of pascals $(\mathrm{Pa})$. Acoustic wavelengths at frequencies greater than $10 \mathrm{kHz}$ are generally small compared to the relief of the water-sediment interface, and bottom echoes are incoherent, varying significantly in amplitude and shape as the sonar translates longitudinally above the interface. Because of this variability, echoes must be treated stochastically.

For comparison with the temporal model, an ensemble of $M$ contiguous returns is characterized by the average echo sequence $\left(p_{a}[n], n=0,1, \ldots, N-1\right)$. To this end, a twodimensional amplitude array $p[m, n]$ is defined for $(0 \leqslant n$ $\leqslant N-1)$ samples per ping and $(0 \leqslant m \leqslant M-1)$ pings, incorporating segments of the data presented in Sec. IV

$$
p_{a}[n]=\frac{1}{M} \sum_{m=0}^{M-1} p[m, n], \quad n=0,1, \ldots, N-1 .
$$

Samples in the echo envelopes from the incoherent returns are Rayleigh distributed, but their ensemble average over many pings is approximately Gaussian. Hence, samples of the average echo envelope are Gaussian distributed. The $N \times N$ covariance matrix $C$ of the average echo is estimated by normalizing the data sample covariance by the number of returns $(M)$. Elements of $C$ are thus

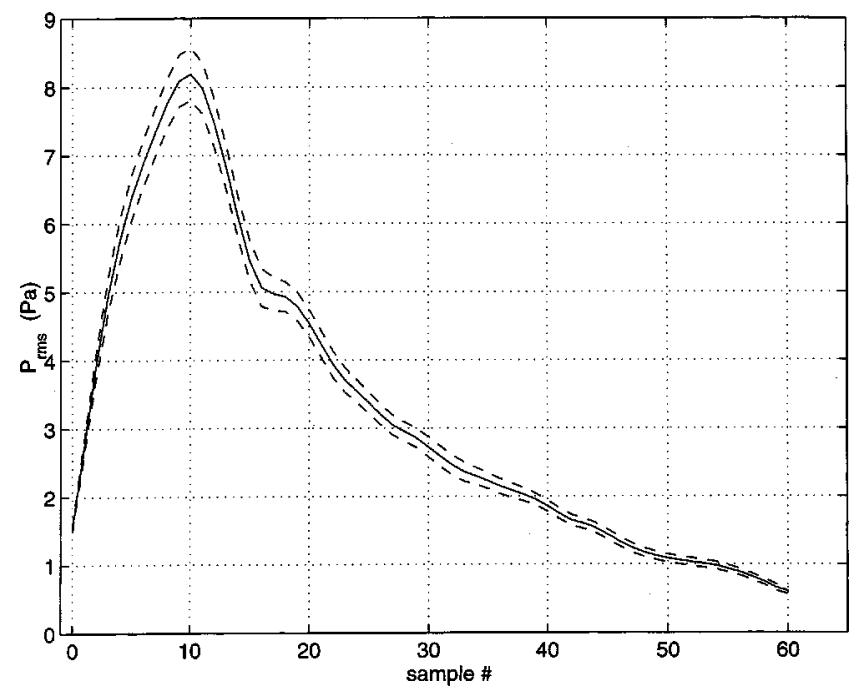

FIG. 1. Average echo envelope for silt substrate: $f_{a}=33 \mathrm{kHz}$, maximum response axis at $8^{\circ}$ incidence. Solid line is $p_{a}[n]$ [Eq. (2)], dashed lines are $p_{a}[n] \pm \sigma_{a}[n]$.

$C_{i j}=\frac{1}{M}\left\{\frac{1}{M-1} \sum_{m=0}^{M-1}\left(p[m, i]-p_{a}[i]\right)\left(p[m, j]-p_{a}[j]\right)\right\}$,

where $(0 \leqslant i, j \leqslant N-1)$. Henceforth, $C$ is referred to as the data covariance matrix.

To focus this description, we use the average echo for 100 consecutive returns measured from a vessel underway over a silt substrate in San Diego Bay, plotted in Fig. 1. Prior to averaging, the echoes were aligned along their respective threshold indices as described in Ref. 13. The average echo envelope is bracketed by $p_{a}[n] \pm \sigma_{a}[n]$, where variances $\sigma_{a}^{2}[n]$ correspond to the diagonal elements of $C$. Plots of $C$ and its corresponding correlation coefficient matrix $Y$, with elements: $\Upsilon_{i j}=C_{i j} / \sigma_{a}[i] \sigma_{a}[j]$ (Fig. 2) show that the variance is proportional to signal strength and that neighboring samples are highly correlated. In later sections, synthetic data sets generated with $C$ will help assess the effects of signal variability on the model-data matching procedure.

The average echo is summarily matched by a temporal model estimate $\left(\hat{p}_{a}[n]\right)$ generated with specified mean altitude and sediment geoacoustic parameters

(a)

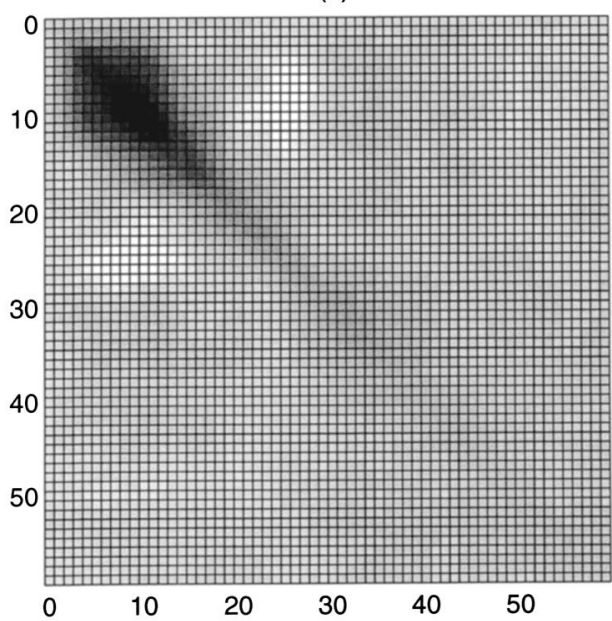

(b)

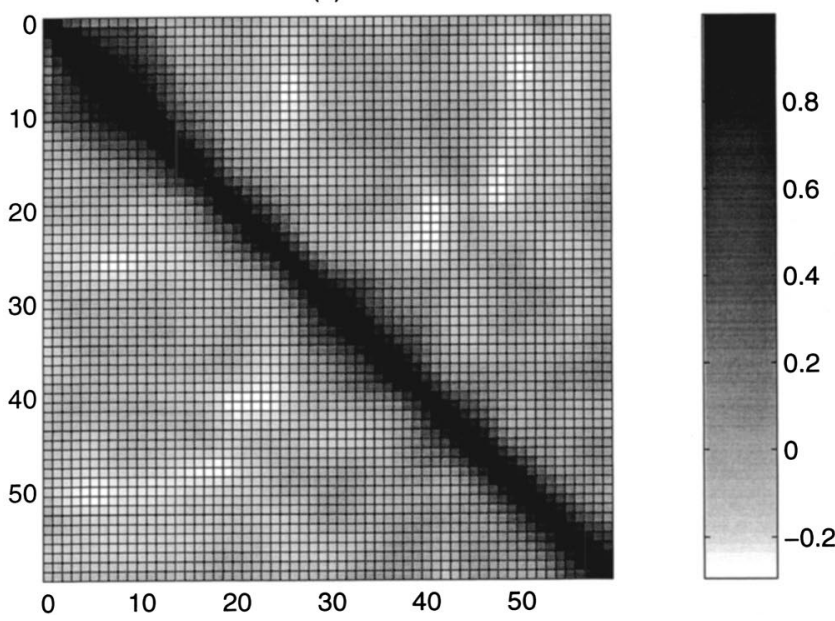

FIG. 2. (a) Data covariance matrix [Eq. (3)], and (b) Correlation coefficient matrix, for average echo envelope of Fig. 1. 


$$
\hat{p}_{a}[n]=\sqrt{\rho_{w} \nu_{w} \hat{I}_{a}[n]},
$$

where $\hat{I}_{a}[n]$ represents the discrete implementation of the echo envelope model, and $\rho_{w}$ and $\nu_{w}$ correspond to seawater density and sound speed, respectively.

To measure the fit between the model and data, a merit function compares the total energy in the average echo, $p_{a}[n]$, to a measure of energy representing the discrepancy between model and data. This signal to error ratio (S/E) is expressed as

$$
\mathrm{S} / \mathrm{E}=\frac{\sum_{n=n_{1}}^{n_{2}} p_{a}^{2}[n]}{\sum_{n=n_{1}}^{n_{2}}\left(p_{a}[n]-\hat{p}_{a}[n]\right)^{2}},
$$

where $n_{1}$ and $n_{2}$ are the initial and final indices for both waveforms. In this scheme a high value of $\mathrm{S} / \mathrm{E}$ signifies a "good" match of model with data. This method provides numerical evaluations which are independent of scale and signal length, and is convenient for comparing results between data sets.

\section{GEOACOUSTIC PARAMETER ESTIMATION}

The estimation of bottom characteristics from the temporal model depends on a model-data matching paradigm (Fig. 3) that converges to a unique and correct set of bottom parameters. The bottom characteristics which describe the data are determined by comparing the model to the average bottom echo, with the goal of minimizing the error to signal ratio (E/S), i.e., the inverse of Eq. (5). However, estimation of geoacoustic parameters is complicated by the large number of good fits existing in the multidimensional search space, where it is possible to find convincing model-data fits which do not necessarily represent correct solutions. ${ }^{13}$ Arriving at sensible solutions requires parsing the problem into manageable parts, establishing the degree of parameter correlations, and constraining the search space.

\section{A. Two-stage parametric optimization}

With the goal of deriving unambiguous matches between the temporal model and data, we initially experimented with a one-dimensional (1D) search technique, ex-

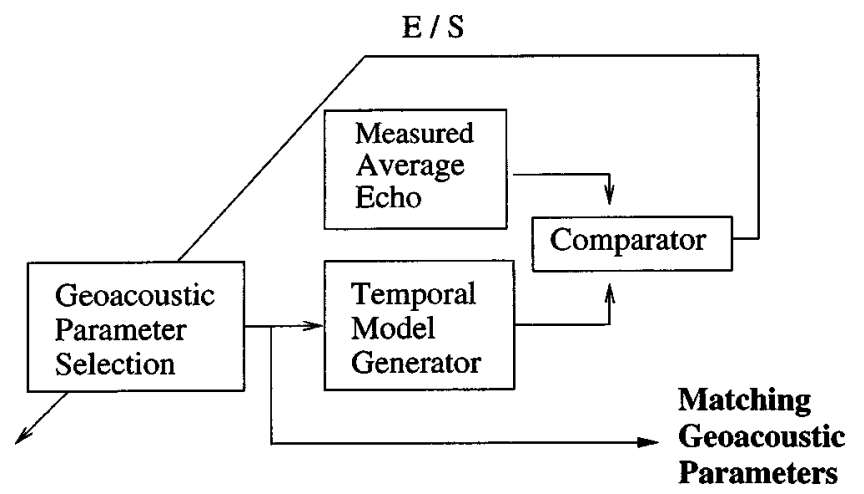

FIG. 3. Geoacoustic parameter optimization procedure: The comparator feeds back (E/S) to the parameter selection module to guide the selection of more promising parameter settings. The system outputs model parameters corresponding to the optimal fit. Careful implementation of the parameter selection module determines the success and tractability of this matching procedure. tracting the best-fit generic characteristics by iterating on the mean grain size parameter $\left(M_{\phi}\right)$. Here, the six geoacoustic parameters $\left(w_{2}, \gamma, \sigma_{v}, \rho, \nu, \kappa_{p}\right)$ are related to $M_{\phi}$ through linear regression formulas adapted from Refs. 17, 18 and summarized in Appendix A of Ref. 13. As was demonstrated in Ref. 21, the generic parameters produce rough modeldata fits for the San Diego Bay substrates investigated. It follows that the solution produced with the 1D search defines a seed vector $\left(M_{\phi}, w_{2}, \sigma_{v}\right)$ appropriate for a second-stage multiparameter search in which $\gamma$ is held to a constant. For the second stage, multiparameter local optimization techniques yielded disappointing results marked by convergence to solutions which were unstable and overly sensitive to the choice of seed vector. This led to the development of a model-data matching procedure incorporating the $1 \mathrm{D}$ search to establish the general sediment type (sand or fines) and the spectral exponent $(\gamma)$, followed by a three-dimensional (3D) global optimization using a combination of simulated annealing and downhill simplex searches (SA/DS) over the roughness spectral strength $\left(w_{2}\right)$, the sediment volume scattering coefficient $\left(\sigma_{v}\right)$, and the mean grain size $\left(M_{\phi}\right)$ associated with the correlated parameters: $\rho, \nu, \kappa_{p}$.

\section{Stage 1: 1D golden section search and parabolic interpolation}

For transducer orientations close to normal incidence, the bottom reflection coefficient is the dominant factor determining the signal amplitude. It follows that the model vs data search space generally has one extremum when described by the single parameter $M_{\phi}$. This situation is illustrated by the E/S vs $M_{\phi}$ plot of Fig. 4(a), where the "best" solution is found by iteratively bracketing the minimum. For this purpose, we employ a combination of the golden section search algorithm coupled with inverse parabolic interpolation, a procedure formulated in Ref. 22. The geoacoustic parameter outputs of stage 1 provide a starting point for the multiparameter global search technique of stage 2 .

\section{Stage 2: Global simulated annealing—downhill simplex optimization (SA/DS)}

After testing a number of local multiparameter search techniques, we found nongreedy, nonexhaustive search procedures to be most appropriate for finding the best-fit geoacoustic parameters. These techniques investigate regions of the parameter space not typically visited by local search techniques, thus increasing the prospects that a true global

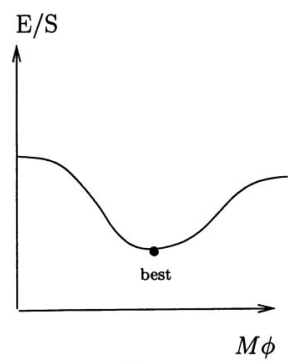

(a)

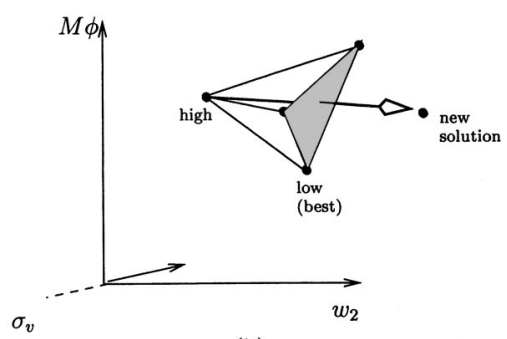

(b)
FIG. 4. Parameter space representations for optimization algorithms: (a) 1D search space, E/S vs $M_{\phi}$; (b) Reflection across the face of a three parameter simplex. 


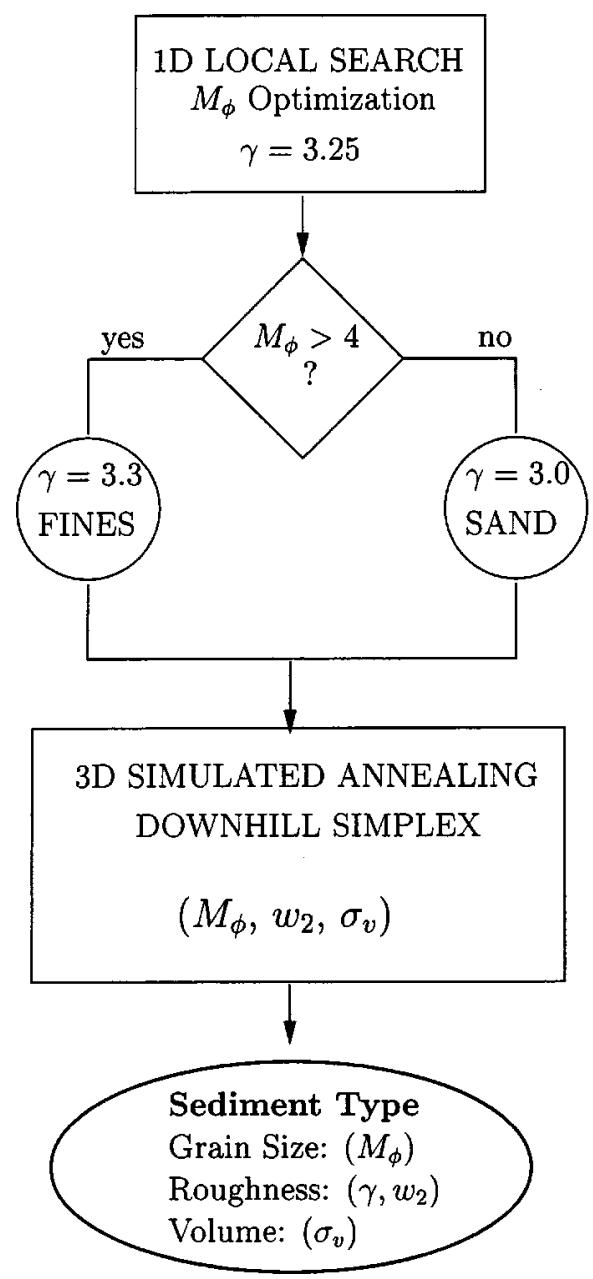

FIG. 5. Flow chart for parameter estimation.

minimum will be found. In simulated annealing the system is initialized to some high-energy state and then slowlybrought to the zero state, where a final local search is performed.

A variety of annealing techniques exists, with common reliance on randomly generated numbers for selection of new parameter vectors. We initially tested the best-known version, described in Ref. 23. This method employs the Metropolis algorithm, ${ }^{24}$ for which randomly generated parameter vectors, yielding a lower cost than the current vector, are automatically accepted, while those yielding a higher cost are accepted by condition of the Boltzmann probability distribution

$$
P(\Delta E)=\exp (-\Delta E / T),
$$

where $\Delta E$ signifies a positive increase in energy at temperature $T$. If the search space is vast and/or if calculation of the objective function is computationally intensive, convergence for this method may be unacceptably slow.

Although the temporal model lacks analytic derivatives, it is continuous in the sense that a small change in parameter value is accompanied by a proportional change in the cost function. With this information, faster convergence to a global minimum may be achieved by employing the NelderMead downhill simplex search, modified by random temperature-dependent uphill energy transitions as described in Ref. 25. For a solution space comprised of three parameters $\left(M_{\phi}, w_{2}, \sigma_{v}\right)$, a simplex of four solution vectors is cre- ated as illustrated in Fig. 4(b). The cost function E/S is minimized by reflections, contractions, and expansions of the simplex where, at high temperatures, nonoptimal solutions are occasionally accepted into the simplex at the expense of better solutions. At the final temperature stage $(T=0)$ the simplex is assumed to be in the vicinity of the global minimum, and the Nelder-Mead algorithm is applied in its original form, only accepting better solutions (local search). To maximize the algorithm's effectiveness, the best solution found since initiation of the search is preserved throughout the annealing process.

\section{B. Parameter estimation paradigm}

The geoacoustic parameters contained in the temporal model define a complicated search space with numerous local minima. It is thus essential to constrain the solution space using a priori knowledge, and to employ practical heuristics in order to reject implausible solutions. For extracting unique and meaningful sediment parameters from the shape and amplitude of measured bottom echoes, we propose the parameter estimation paradigm illustrated by the flow chart of Fig. 5. This technique represents an automated version of the model-data matching guidelines proposed in Ref. 13, where the result of the initial 1D local search (top module of the flow chart) provides the a priori information needed to constrain the second stage. The $M_{\phi}$ result is fed to a decision junction which determines the general bottom type (sands or fines) and sets the roughness spectral exponent $(\gamma)$ in preparation for the multiparameter optimization. The 3D global $\mathrm{SA} / \mathrm{DS}$ procedure iterates over a limited range of $M_{\phi}, w_{2}$, and $\sigma_{v}$, fine-tuning the impedance contrast, roughness spectral strength, and volume estimates for the substrate. The final result of this procedure provides the general substrate type (sand vs fines), bottom characteristics $\left(M_{\phi}, \gamma, w_{2}, \sigma_{v}\right)$, and, indirectly, the sediment geoacoustic parameters correlated to mean grain size.

It should be noted that the search space for the second stage optimization is constrained by restricting the mean grain size to $\left(\check{M}_{\phi}-1\right) \leqslant M_{\phi} \leqslant\left(\check{M}_{\phi}+1\right)$, where $\check{M}_{\phi}$ represents the seed value from stage one. When contortion of the SA/DS simplex violates these bounds, a suitable penalty is added to the E/S cost function to reject out-of-bound parameter vectors. Broad bounds are similarly applied to the $w_{2}$ search space to avoid values unsuitable for the numerical integrations carried out by the temporal model algorithm.

The most important condition imposed on the volume scattering coefficient is $\left(\sigma_{v} \geqslant 0\right)$. However, unreasonably large volume components occasionally produce simulated echoes exhibiting low E/S scores. If the maximum volume component is within $2 \mathrm{~dB}$ of the maximum interface component, an empirical penalty, proportional to the severity of this violation, is added to the $\mathrm{E} / \mathrm{S}$ cost function

$$
\begin{aligned}
& \text { IF } I_{v} / I_{i}>0.63 \\
& \text { THEN } \mathrm{E} / \mathrm{S}=\mathrm{E} / \mathrm{S} * 4 *\left\{1+5 *\left(\frac{I_{v}}{I_{i}}-0.63\right)\right\},
\end{aligned}
$$

where $I_{v}$ and $I_{i}$ represent the maximum volume and interface intensities, respectively. This is a reasonable restriction except for oblique incidence measurements over fine-grain sub strates, where it is possible for the volume component to 

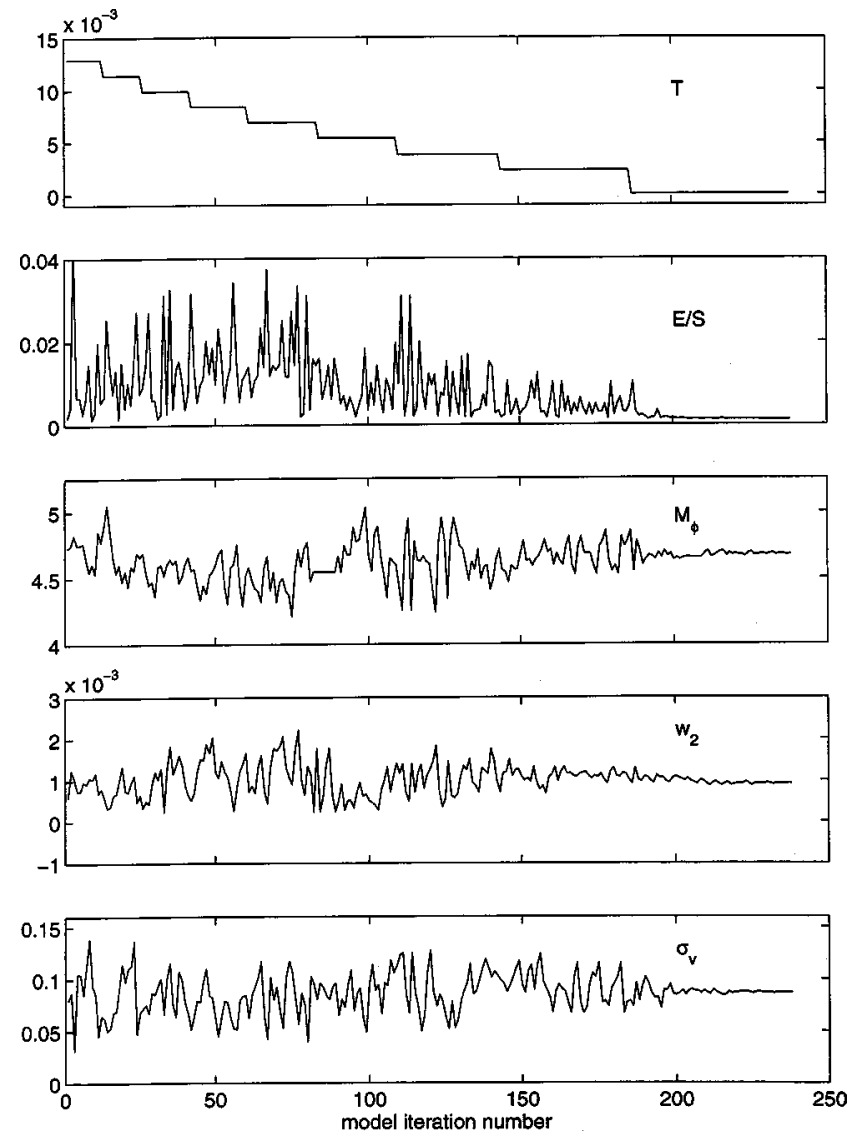

FIG. 6. Annealing process for the data shown in Fig. $1 . w_{2}$ in $\mathrm{cm}^{4}, \sigma_{v}$ in $\mathrm{m}^{-1}$. The parameter values for the first iteration are the output of the $1 \mathrm{D}$ optimization; the final values are the annealing outputs. Note the large variety of nonoptimal solutions investigated before low annealing temperatures constrain the search space. In this particular example, the initial parameters are reasonably close to the final solution.

dominate. In theory, the simulated annealing algorithm converges asymptotically to an optimal solution if the temperature is initially high and allowed to decrease inverse logarithmically with the number of iterations. ${ }^{26}$ However, the computational requirements of the cost function in this model-data matching application require a more conservative number of model iterations. After experimenting with the annealing control parameters, adequate solution accuracy and convergence speed were achieved by employing a hybrid linear-exponential cooling schedule with nine discrete temperature levels. In this scheme, the initial temperature $T_{0}$ is set to the average E/S for the four initial simplex vertices, where one of these vectors (the seed) is derived from the first local-search stage, and the other three are slightly perturbed replicas. Ten model iterations are initially investigated at $T_{0}$ and, for each temperature stage thereafter, the number of iterations increases by $25 \%$, resulting in a total of approximately 230 model iterations (e.g., Fig. 6).

\section{Evaluation of error propagation by Monte Carlo simulation}

For a given bottom substrate, the average echo can vary from data ensemble to data ensemble. To characterize how this variation affects the results of the model-data matching procedure, $K$ synthetic average echo envelopes are generated with random combinations of signal and noise. Lacking

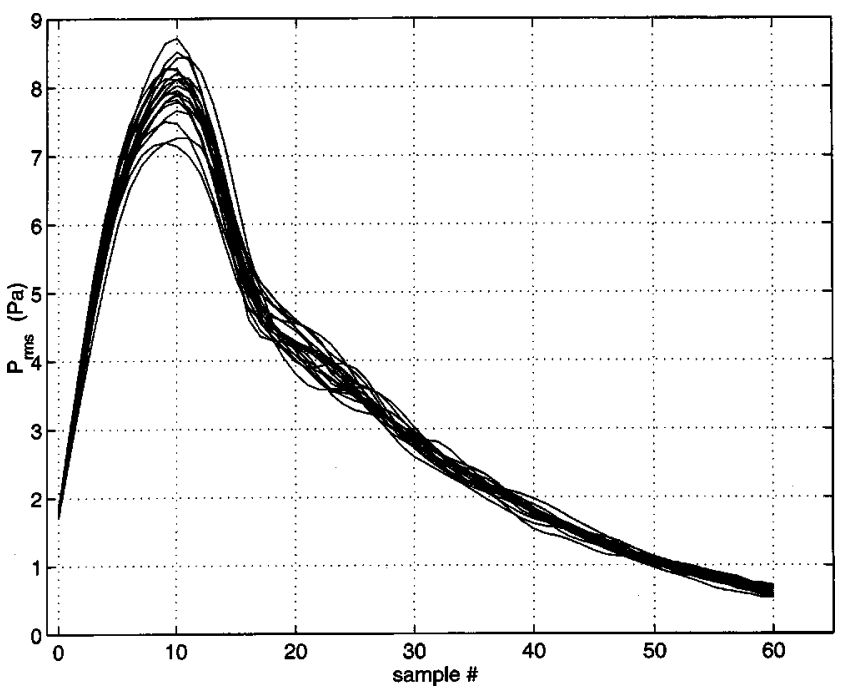

FIG. 7. Monte Carlo simulations for silt substrate in Fig. 1: Model parameters: $f_{a}=33 \mathrm{kHz}, M_{\phi}=4.68, \gamma=3.3, w_{2}=0.0009 \mathrm{~cm}^{4}, \sigma_{v}=0.086 \mathrm{~m}^{-1}$, $\theta_{T}=8^{\circ}, b=1.28$.

knowledge of the "true" signal, the model output resulting from the optimization procedure is distorted by noise characterized in the data's covariance matrix $(C)$. The optimization procedure is applied to each waveform and, using the resulting $K$ solution vectors $\left(M_{\phi}, w_{2}, \sigma_{v}\right)$, an approximation to the $3 \times 3$ parameter covariance matrix is computed and evaluated.

With bold lower case letters used to indicate $1 \times N$ vectors, a simulated average echo envelope $\left(\mathbf{p}_{\mathbf{s}}\right)$ is calculated from: the model output $\hat{\mathbf{p}}_{\mathrm{a}}$, a vector of standard normal random deviates $(\mathbf{x})$, and the upper triangular matrix $(A)$ from Cholesky factorization of the covariance matrix, $C=A^{T} A$

$$
\mathbf{p}_{\mathbf{s}}=\mathbf{x} A+\hat{\mathbf{p}}_{\mathbf{a}} \text {. }
$$

Figure 7 shows $K=20$ synthetic "average" echo envelopes calculated using the best-fit model for the silt substrate data shown in Fig. 1. These simulations were created using the average echo of Fig. 1 and the covariance matrix displayed in Fig. 2. The amplitude deviations and degrees of correlation between neighboring samples are realistic, as comparison with Fig. 1 confirms. The $20\left(M_{\phi}, w_{2}, \sigma_{v}\right)$ solutions yield the following statistics:

\begin{tabular}{llllll} 
Parameter & Original & Mean & Stdv & $\begin{array}{c}\text { Parameter } \\
\text { Pair }\end{array}$ & $\begin{array}{l}\text { Correl } \\
\text { Coeff }\end{array}$ \\
\hline$M_{\phi}$ & 4.68 & 4.67 & 0.10 & $\left(M_{\phi}, w_{2}\right)$ & -0.47 \\
$w_{2}\left(\mathrm{~cm}^{4}\right)$ & 0.00091 & 0.00092 & 0.00022 & $\left(M_{\phi}, \sigma_{v}\right)$ & -0.23 \\
$\sigma_{v}\left(\mathrm{~m}^{-1}\right)$ & 0.086 & 0.078 & 0.003 & $\left(w_{2}, \sigma_{v}\right)$ & -0.14
\end{tabular}

where "Original" refers to the original solution vector. In this example the mean values of the Monte Carlo solutions are similar to the original parameters, the standard deviations are a small percentage of the mean values (with possible exception of $w_{2}$ ), and absolute values of the correlation coefficients are less than 0.5 .

In the following sections, plots of $M_{\phi}$ and $w_{2}$ are used for distinguishing bottom types. Assuming that the solutions are jointly Gaussian distributed, the $90 \%$ error ellipse of $\left(w_{2}\right.$ vs $M_{\phi}$ ) is calculated and plotted in Fig. 8. For this example, the observed echo variability may account for solution intervals: $4.43 \leqslant M_{\phi} \leqslant 4.89$ and $0.0004 \leqslant w_{2} \leqslant 0.0014$. 


\section{SHALLOW-WATER SURVEYS}

The sonar system described in Refs. 21, 27 was developed to evaluate the accuracy of the temporal model and its potential for bottom classification over a range of acoustic frequencies and transducer orientations. Circular piston geometries were chosen for their symmetrical directivity patterns, with beamwidths of $21^{\circ}$ at $33 \mathrm{kHz}$ and $10^{\circ}$ at $93 \mathrm{kHz}$, so that for each transducer orientation, an adequate range of bottom incident angles could be insonified by a single short pulse of $0.45 \mathrm{msec}$ at $33 \mathrm{kHz}$ and $0.16 \mathrm{msec}$ at $93 \mathrm{kHz}$.

For meaningful comparison of model and data, the temporal model utilizes a digitized representation of the transmitted signal, and measured voltage waveforms are converted to their respective pressure waveforms using the transducer's mechanical-electrical transfer function. ${ }^{21,27}$

\section{A. Survey site}

In January and May of 1997, the dual-frequency echosounder was installed in the instrument well of the $40-\mathrm{ft}$ research vessel ECOS, operated by the Space and Naval Warfare Systems Center (SPAWAR). To validate the temporal model and determine the optimum survey configuration for substrate identification, bottom echoes were recorded from a range of sediment types with the $33-$ and $93-\mathrm{kHz}$ transducers inclined $0^{\circ}$ to $16^{\circ}$ from nadir in the roll plane. Data were measured over three sites in San Diego Bay consisting, respectively, of sand, silt, and clay substrates.

Bottom characterization was based on: (1) video coverage recorded during the survey; (2) consulting a sediment data base for the surrounding area; and (3) analysis of particle size distribution for sediment grabs taken during the survey. Sediment samples were separated into size components using sieve separation and pipette settling procedures outlined in Ref. 28. The particle size analyses of these sites are catalogued in the Appendix, Table IV. At these sites, sand particles constituted the largest grain size percentage; however, labels of sand, silt, and clay were determined using the calculated $M_{\phi}$ values and observed physical characteristics of the samples.

The sand site consisted of a 50-m N-S trackline running along the jetty at the mouth of San Diego Bay, in water depths of 13-15 m, with mean grain size distributions $M_{\phi}$ $=2$, or medium-fine sand according to the labeling scheme set forth in Ref. 17. The video images revealed an isotropic bottom characterized by hillocks with crest-trough heights of $40 \mathrm{~cm}$ or more over wavelengths of about $8 \mathrm{~m}$, a light sprinkling of shell hash, and an occasional starfish or blade of kelp.

The silt site consisted of a $150-\mathrm{m} \mathrm{N}-\mathrm{S}$ trackline of the San Diego Bay trough - the deepest part of the bay with water depths of 15-20 m-whose substrate ranged between clayey sand and sandy mud. ${ }^{17}$ The video images revealed long stretches of homogeneous substrate, occasional patches of kelp, and sole blades of sea grass.

The clay site consisted of a 50-m E-W trackline running just north of San Diego Bay's North Island, water depths of 11-13 m, with mean grain size distributions $M_{\phi}=7.0$, or sandy clay. ${ }^{17}$ The grain-size analysis identifies this sediment as borderline silt-clay, but we categorize it as clay because of the relatively smooth seascape observed, and the pasty, waterlogged character of the physical samples. The bottom video revealed a featureless, isotropic bottom, with little flora or fauna except for what appeared to be small burrows less than a centimeter in diameter.

The uncomplicated appearance of these three substrates, the high spatial overlap between consecutive pings, and the generally level bathymetry, were conditions deemed sufficient for testing the accuracy of the temporal model.

\section{B. Data}

The acoustic survey for each site was carried out at speeds of 1-2 kn, ping repetition rate of $5 \mathrm{~Hz}$, and horizontal displacements of about $0.1 \mathrm{~m}$ per ping. The transducer was elevated to a specified angle from nadir in the roll plane. Angles of pitch and roll were digitized for each ping repetition and used, along with knowledge of local bathymetry, to determine the angle of incidence $\left(\theta_{T}\right)$ of the transducer's maximum response axis on the bottom. Sea conditions were generally mild, with pitch and roll standard deviations typically less than $0.5^{\circ}$.

Echoes from the San Diego Bay substrates measured at 33 and $93 \mathrm{kHz}$ are plotted in Figs. 9 and 10. A total of 12 scenarios is analyzed, each characterized by a unique combination of acoustic frequency, sediment type, and transducer orientation (Appendix, Table V). It is tempting to interpret the raster images (Figs. 9, 10) as true geophysical cross sections of the bottom; however, penetration at these high acoustic frequencies is limited and the observed energy is due primarily to scattering from the water-sediment interface.

The raster image of Fig. 9(c) shows a 30-m track segment with a gradual downward slope of the bottom, modulated by the vessel's heave-whose removal is essential for echo alignment and averaging. In contrast, the 40cmdepth fluctuations apparent in Fig. 10(a) represent actual topography. Therefore, these data sets require a level of scrutiny to identify artifacts that can unfairly bias the shapes and amplitudes of the backscattered echoes. Objects protruding from or suspended over the bottom may cause scattering

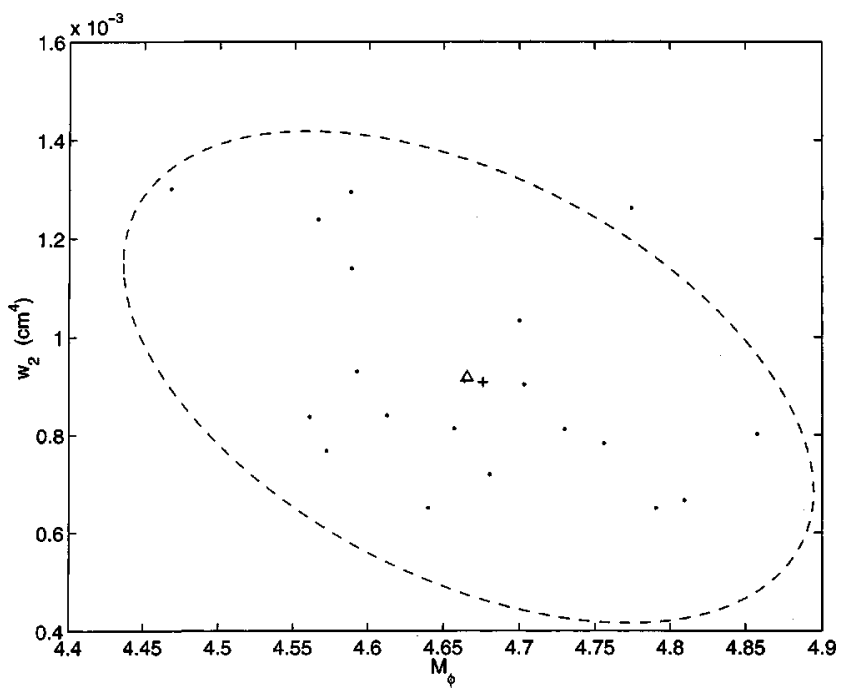

FIG. 8. Scatter plot $\left(w_{2}\right.$ vs $\left.M_{\phi}\right)$ and $90 \%$ error ellipse for Monte Carlo simulations. (.) Monte Carlo solutions; $(\triangle)$ mean of Monte Carlo solutions; $(+)$ original solution. 
NORMAL INCIDENCE
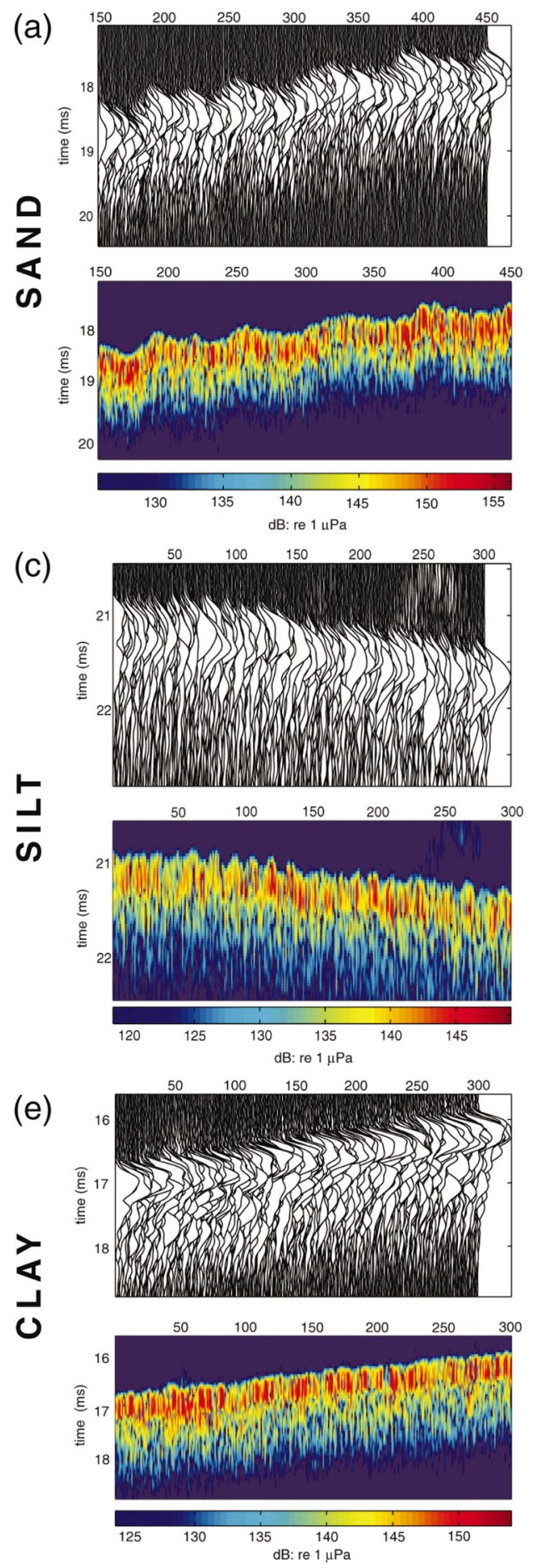

OBLIQUE INCIDENCE

(b)
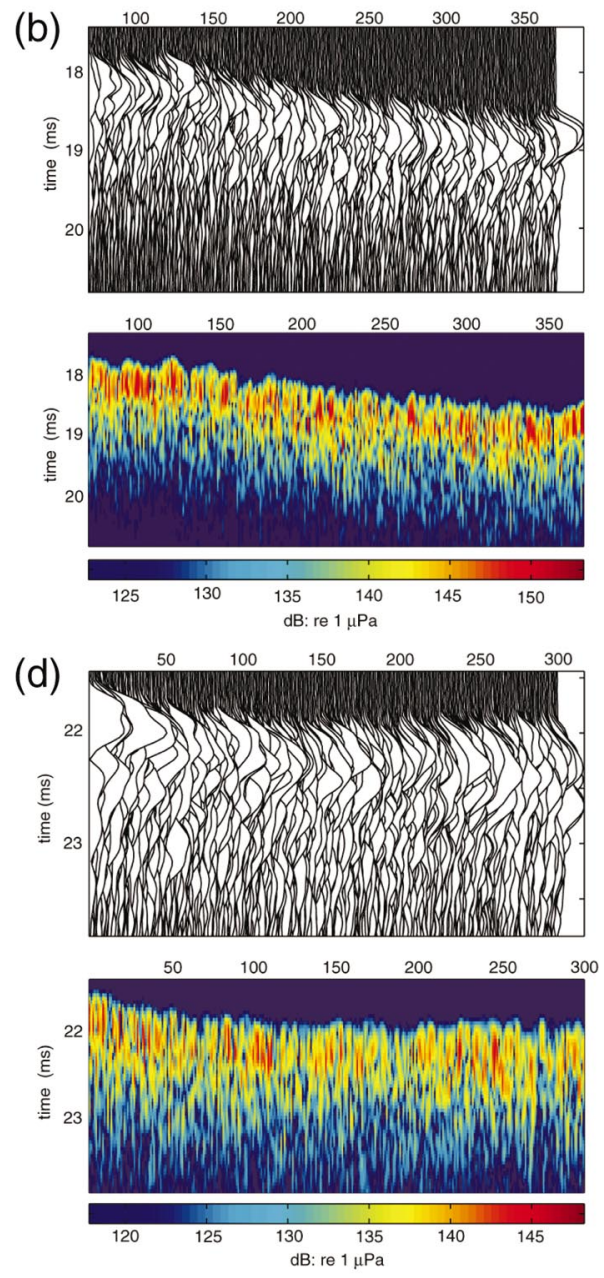

(f)
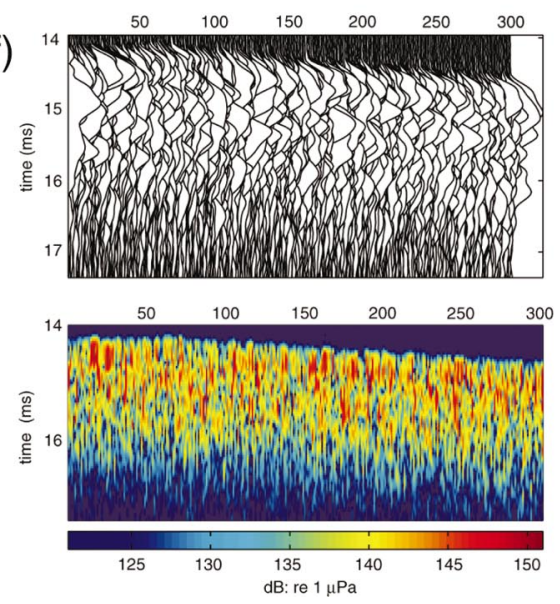

FIG. 9. Waterfall and raster plots for 300 consecutive pings of $33-\mathrm{kHz}$ data. Left: normal incidence, Right: oblique incidence. $y=$ time in ms since transmit, $x=$ ping number. anomalies and/or reduced signal levels. The early returns evident in pings 230-280 of Fig. 9(c) are most likely caused by a school of fish swimming near the bottom. Similarly, the scattered energy preceding the bottom profile in pings 430460 of Fig. 10(e) is a strong indication of flora anchored to the sediment. Bubbles on the face of the transducer can cause temporary dropout of signal amplitude, as evident in pings $80-100$ of Fig. 10(b). Data segments clearly exhibiting the artifacts described above are rejected.

Segments of these data sets are combined into an aver- age echo envelope (average pressure vs time) for comparison with the temporal model.

\section{OPTIMUM FITS OF MODEL WITH DATA}

The two-stage parameter estimation technique described in Sec. III was applied to average echo envelopes from the

12 scenarios presented in Sec. IV B. A group delay echo alignment technique was applied to $93-\mathrm{kHz}$ oblique incidence measurements made over sand and silt, and minimum 


\section{$93 \mathrm{k} \mathrm{H} \mathrm{z}$}

NORMAL INCIDENCE
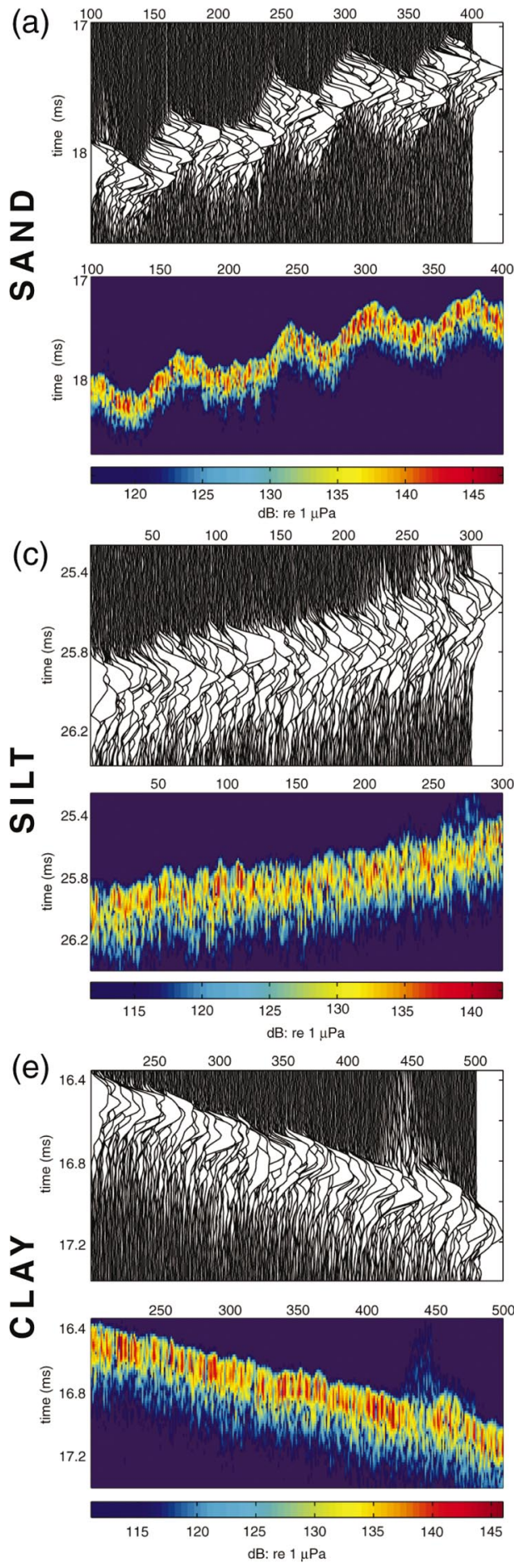

OBLIQUE INCIDENCE
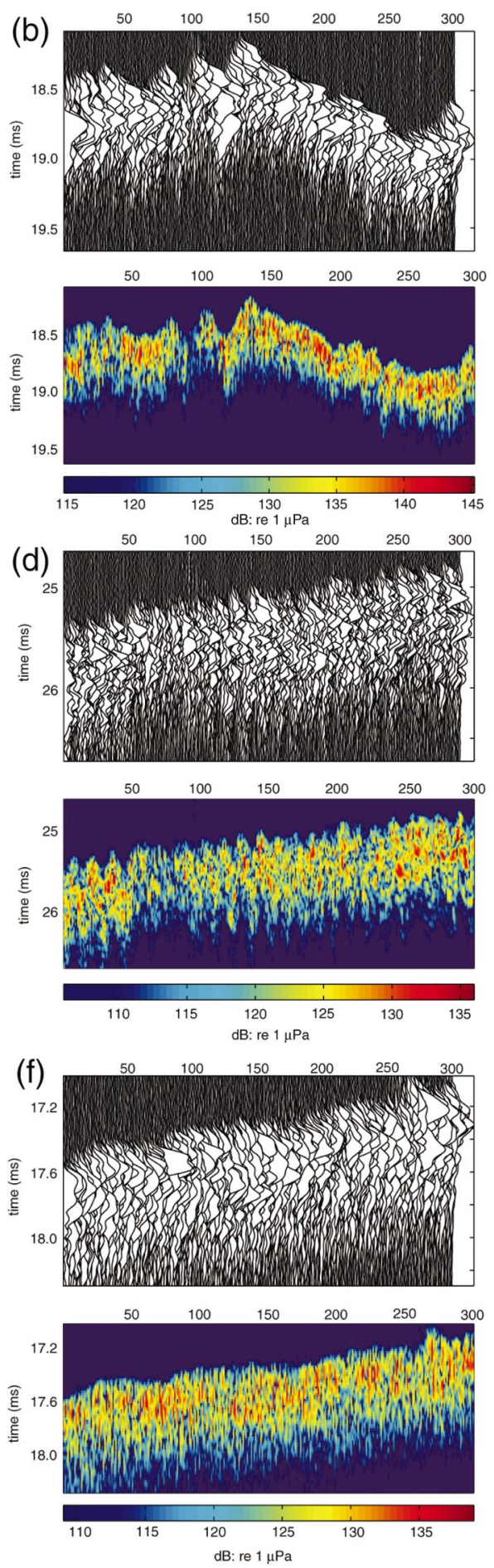

FIG. 10. Waterfall and raster plots for 300 consecutive pings of $93-\mathrm{kHz}$ data. Left: normal incidence, Right: oblique incidence. $y=$ time in ms since transmit, $x=$ ping number. threshold alignment was used for all other scenarios. Details of the echo alignment techniques are given in Ref. 13.

The volume scatter penalty [Eq. (7)] is applied in all the scenarios, except for $93-\mathrm{kHz}$ oblique incidence measurements on clay and silt. For the latter, large volume contributions are expected to dominate the signal amplitude when transducer elevation angles are large relative to the beamwidth, and in conditions of increased bottom penetrationsuch as water-saturated sediment and/or low acoustic frequencies.
For each scenario, approximately ten model-data matches were determined with $50 \%$ or less overlap between data segments. A summary of model-data matches is presented in Table I. First- and second-order statistics of the results are listed in the Appendix, Tables VI and VII.

To determine the best prospects for sediment classification, we evaluated parameter estimates for the four measurement combinations (two acoustic frequencies, two transducer orientations) and concluded that scatter plots of $w_{2}$ vs $M_{\phi}$ effectively delineate the bottom substrates (Figs. 11, 12). 
TABLE I. Sediment classification summary. Mean values are rounded off to the nearest one-tenth value. Geoacoustic parameters $\left(\rho, \nu, \kappa_{p}\right)$ are calculated from $M_{\phi}$ with relationships described in Ref. 13.

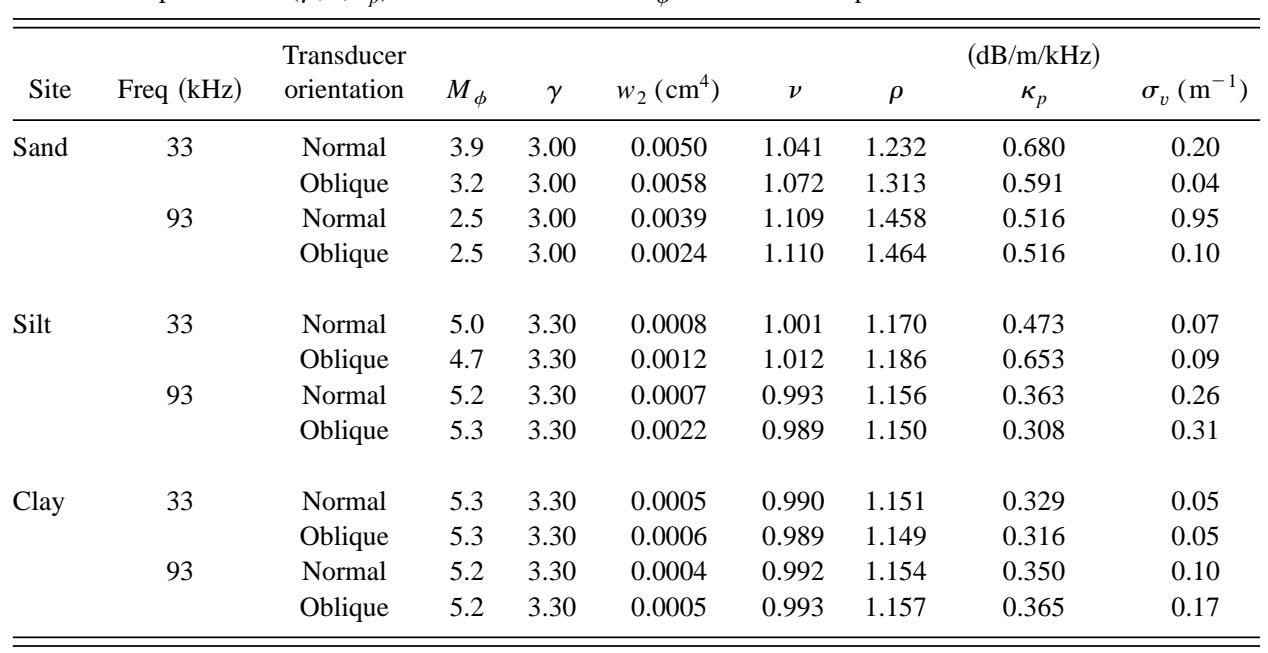

\section{A. Mean grain size $\left(M_{\phi}\right)$ vs relief spectrum strength $\left(w_{2}\right)$}

On the whole, estimated values of mean grain size $\left(M_{\phi}\right)$ agree with ground-truth measurements presented in Appendix Table IV, and model-data matches for silt exhibit the most consistency across acoustic frequency and transducer orientation. The 33-kHz $\left(M_{\phi}\right)$ estimates for sand are high, approaching the range characteristic of silts. This may be due to local deviation of impedance contrast from the generic values employed by the model-data matching technique-an
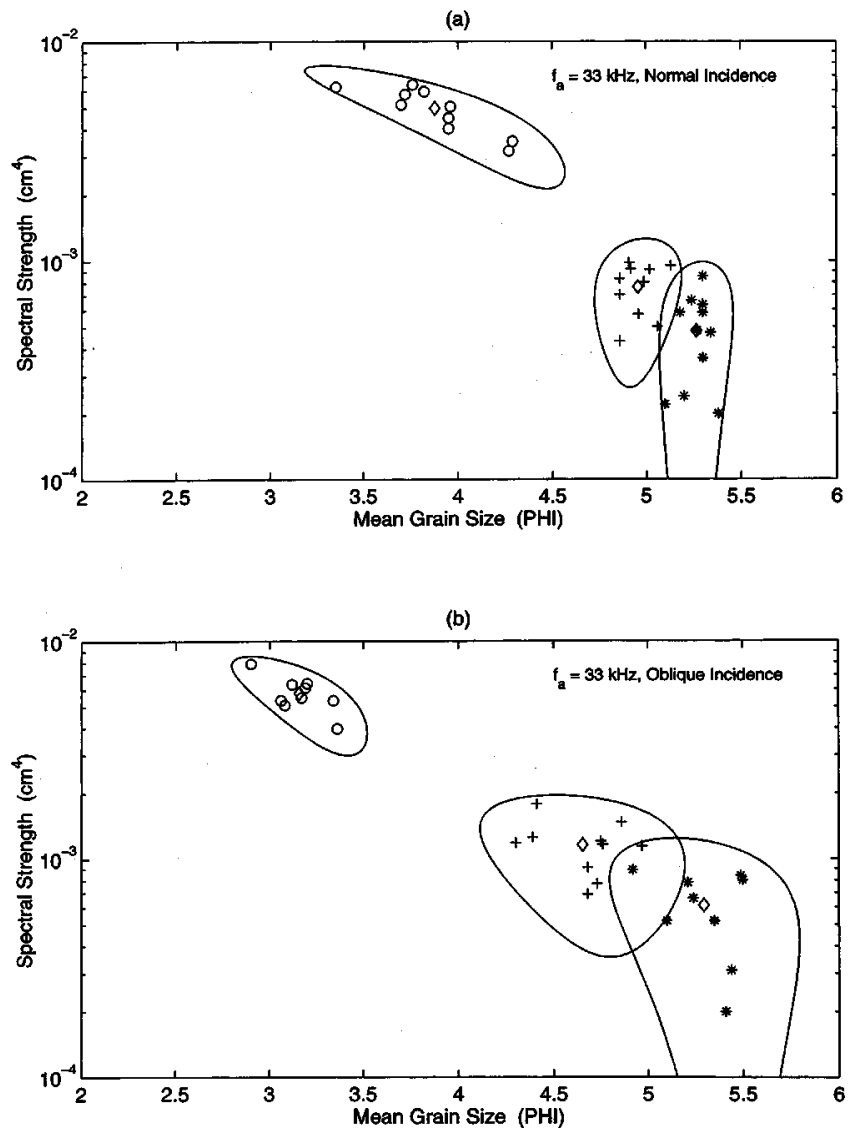

FIG. 11. Scatter plot of model-data matches at $33 \mathrm{kHz}$ : Site locations: $(\bigcirc)$ Sand; $(+)$ silt; $(*)$ clay; $(\diamond)$ mean value and center of $90 \%$ confidence region (solid line). Transducer orientation: (a) Normal; (b) Oblique. inference supported by sediment density measurements described in Refs. 29,30 . As the estimated $\left(M_{\phi}\right)$ parameter is especially sensitive to changes in measured echo amplitude, errors in field calibration may also contribute to disagreements between model-data matches and ground truth.

Mean grain size $\left(M_{\phi}\right)$ estimates for the clay site $(\sim 5.3)$ are lower than the ground-truth values $(>6.5)$ because the volume signal component is overestimated, due to the sharp decrease of the sediment acoustic attenuation constant $\left(\kappa_{p}\right)$ correlated with high values of $M_{\phi} \cdot{ }^{17}$ For these fine-grain sediments, accurate $M_{\phi}$ matching is limited, and applying locally determined $\left(\rho, \nu, \kappa_{p}\right)$ trends would probably produce more realistic model-data matches.

Mean grain size $\left(M_{\phi}\right)$ estimates for sand exhibit greater variability than for fines, with measures of standard deviation ranging from 0.14 to 0.44 , and $90 \%$-confidence regions spanning as many as three gradations. In general, $M_{\phi}$ estimates for silt and clay exhibit more modest ranges, with standard deviations spanning 0.08 to 0.38 .

As seen in Table VI and Figs. 11, 12, estimates of roughness spectral strength $\left(w_{2}\right)$ are greater than 0.001 for the sand site, less than 0.001 for the clay site, and about 0.001 for the silt site. This trend follows the logic that the relief energy density spectra of coarse-grain sediments have more energy than those of fine-grain sediments. Variation in the estimate of $w_{2}$ appears greater in fines than in sands. As a percentage of the mean value, $w_{2}$ standard deviations for fine-grain sediments $(24 \%-56 \%)$ are typically larger than those for sand $(19 \%-38 \%)$.

Note from Table VII and Figs. 11, 12 that anticorrelation of $M_{\phi}$ and $w_{2}$ is also a general bias of the model-data matching procedure. This is especially true of sand measurements, where $\left(M_{\phi}, w_{2}\right)$ correlation coefficients range from -0.58 to -0.96 , causing the pronounced slope in the sand confidence regions.

In the literature there is agreement that bottom scattering measurements can be matched to general bottom classes (fines, sand, gravel, rock) $;^{31}$ however, correlation of scattering strength to grain size distribution is thought to be weak within each sediment class. The variability in the individual echo amplitudes that we measured confirms this. If, as indi- 
(a)

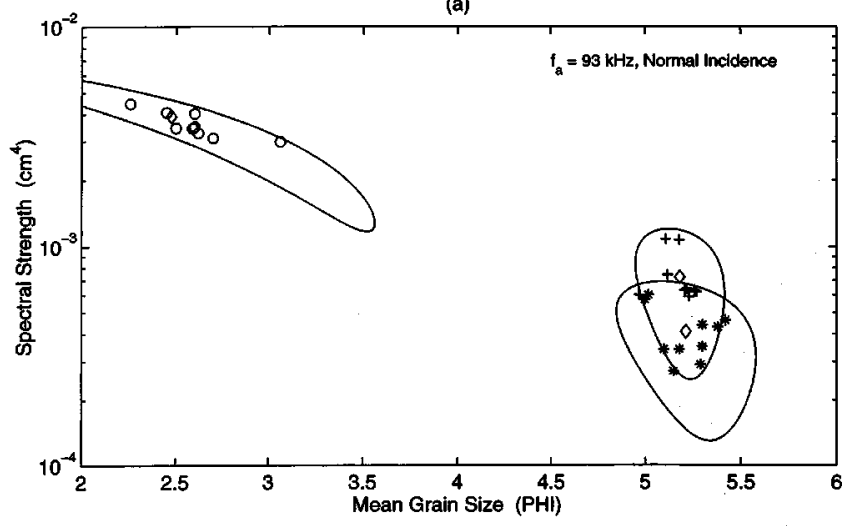

(b)

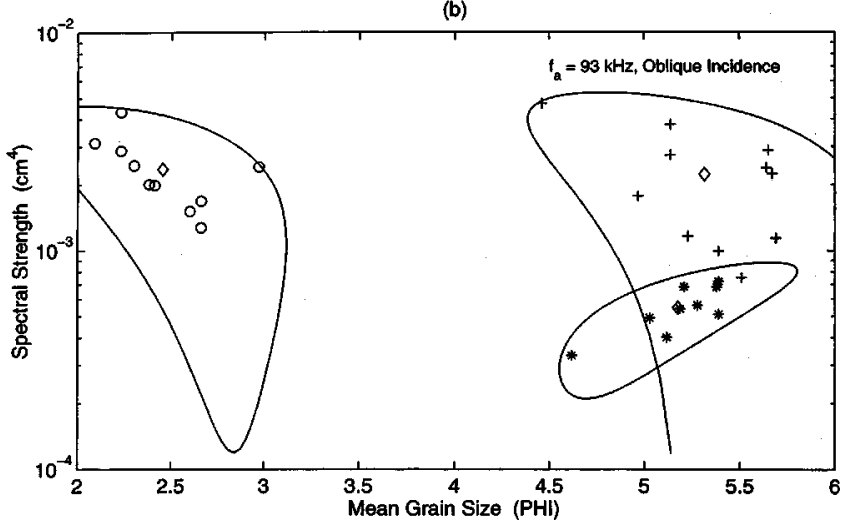

FIG. 12. Scatter plot of model-data matches at $93 \mathrm{kHz}$ : Site locations: $(\bigcirc)$ Sand; $(+)$ silt; $(*)$ clay; $(\diamond)$ mean value and center of $90 \%$ confidence region (solid line). Transducer orientation: (a) Normal; (b) Oblique.

cated in this analysis, interface roughness characteristics and grain size distributions were complementary, evaluation of echo shape may allow a degree of intraclass separation.

\section{B. Sediment volume scattering coefficient $\left(\sigma_{v}\right)$}

Estimates of the volume scattering coefficient $\left(\sigma_{v}\right)$ are perhaps the most difficult to interpret and, as seen in Table $\mathrm{VI}$, standard deviations on the order of $3 \mathrm{~dB}$ from the mean value are not uncommon. This variation may be due to real changes in the statistics governing neighboring patches of seafloor. The rough $\sigma_{v}$ frequency dependencies inferred from our acoustic backscatter measurements at normal and oblique incidences over sediments in San Diego Bay are $f^{1.2}$ for sand and silt, and $f^{1.0}$ for clay. These values are slightly higher than, but not inconsistent with the $f^{0.7}$ trend inferred from the backscatter measurements analyzed in Refs. 14, 32. Note that an $f^{4}$ dependence would indicate Rayleigh scattering from inhomogeneities much smaller than an acoustic wavelength, whereas frequency independence of $\sigma_{v}$ would imply geometric scattering from inhomogeneities significantly larger than the acoustic wavelength, as might be the case for our measurements over clay. Our inferred frequency dependencies indicate that the volume scatterers in the San Diego Bay sediments have a range of sizes both smaller and larger than the acoustic wavelength.

At a given frequency and transducer orientation, estimates of $\sigma_{v}$ are reasonably consistent for the fine-grain sediments. However, for sand, normal incidence values can exceed oblique incidence values by $10 \mathrm{~dB}$. This may indicate a shortcoming in the model assumption that $\sigma_{v}$ is uniform near the sediment-water interface. If $\sigma_{v}$ increases with depth, estimated values at normal incidence will appear larger than those for oblique incidence. This is due to acoustic penetration at normal incidence to depths where $\sigma_{v}$ is larger-an interpretation consistent with the observations of Refs. 30, 33.

\section{EFFECTS OF ECHO VARIABILITY}

Changes in bottom characteristics as well as echo variability due to random constructive/destructive interferences and scattering centers contribute to the observed spread in parameter estimates (Figs. 11, 12). The length scale of the survey and the averaging of 100 pings (corresponding to roughly the along-track extent of the beam's -6-dB footprint) removes some of the "natural" variability in the individual ping echoes. To investigate the effects of residual echo variability on the outputs of the model-data matching

TABLE II. Monte Carlo statistics.

\begin{tabular}{|c|c|c|c|c|c|c|c|c|c|c|c|c|}
\hline Site & Freq $(\mathrm{kHz})$ & $\begin{array}{l}\text { Transducer } \\
\text { orientation }\end{array}$ & $\begin{array}{c}\text { Original } \\
M_{\phi}\end{array}$ & $\begin{array}{c}\text { Mean } \\
M_{\phi}\end{array}$ & $\begin{array}{l}\text { Stdv } \\
M_{\phi}\end{array}$ & $\begin{array}{c}\text { Original } \\
w_{2} \\
\left(\mathrm{~cm}^{4}\right)\end{array}$ & $\begin{array}{c}\text { Mean } \\
w_{2} \\
\left(\mathrm{~cm}^{4}\right)\end{array}$ & $\begin{array}{c}\mathrm{Stdv} \\
w_{2} \\
\left(\mathrm{~cm}^{4}\right)\end{array}$ & $\begin{array}{c}\text { Original } \\
\sigma_{v} \\
\left(\mathrm{~m}^{-1}\right)\end{array}$ & $\begin{array}{c}\text { Mean } \\
\sigma_{v} \\
\left(\mathrm{~m}^{-1}\right)\end{array}$ & $\begin{array}{c}\text { Stdv } \\
\sigma_{v} \\
\left(\mathrm{~m}^{-1}\right)\end{array}$ & Fig. \\
\hline \multirow[t]{4}{*}{ Sand } & \multirow[t]{2}{*}{33} & Normal & 3.72 & 3.57 & 0.38 & 0.00575 & 0.00640 & 0.00171 & 0.201 & 0.199 & 0.017 & 13(a) \\
\hline & & Oblique & 3.17 & 3.21 & 0.08 & 0.00549 & 0.00536 & 0.00061 & 0.035 & 0.037 & 0.004 & 13(b) \\
\hline & \multirow[t]{2}{*}{93} & Normal & 2.60 & 2.51 & 0.28 & 0.00349 & 0.00369 & 0.00062 & 0.558 & 0.572 & 0.150 & 14(a) \\
\hline & & Oblique & 2.30 & 2.36 & 0.12 & 0.00246 & 0.00236 & 0.00019 & 0.010 & 0.045 & 0.061 & 14(b) \\
\hline \multirow[t]{4}{*}{ Silt } & \multirow[t]{2}{*}{33} & Normal & 4.99 & 4.99 & 0.05 & 0.00080 & 0.00080 & 0.00022 & 0.065 & 0.069 & 0.006 & $13(\mathrm{c})$ \\
\hline & & Oblique & 4.68 & 4.67 & 0.10 & 0.00091 & 0.00092 & 0.00022 & 0.086 & 0.078 & 0.003 & $13(d)$ \\
\hline & \multirow[t]{2}{*}{93} & Normal & 5.12 & 5.11 & 0.08 & 0.00074 & 0.00076 & 0.00012 & 0.288 & 0.305 & 0.028 & $14(c)$ \\
\hline & & Oblique & 5.23 & 5.16 & 0.07 & 0.00116 & 0.00089 & 0.00034 & 0.226 & 0.273 & 0.013 & $14(d)$ \\
\hline \multirow[t]{4}{*}{ Clay } & \multirow[t]{2}{*}{33} & Normal & 5.27 & 5.27 & 0.04 & 0.00048 & 0.00055 & 0.00018 & 0.059 & 0.067 & 0.005 & $13(\mathrm{e})$ \\
\hline & & Oblique & 5.24 & 5.24 & 0.05 & 0.00066 & 0.00078 & 0.00036 & 0.047 & 0.045 & 0.003 & $13(\mathrm{f})$ \\
\hline & \multirow[t]{2}{*}{93} & Normal & 5.18 & 5.20 & 0.04 & 0.00034 & 0.00033 & 0.00005 & 0.122 & 0.122 & 0.014 & 14(e) \\
\hline & & Oblique & 5.19 & 5.20 & 0.04 & 0.00054 & 0.00053 & 0.00012 & 0.181 & 0.190 & 0.012 & $14(\mathrm{f})$ \\
\hline
\end{tabular}


TABLE III. Monte Carlo: Parameter correlation.

\begin{tabular}{|c|c|c|c|c|c|}
\hline Site & Freq. (kHz) & $\begin{array}{l}\text { Transducer } \\
\text { orientation }\end{array}$ & $\left(M_{\phi}, w_{2}\right)$ & $\left(M_{\phi}, \sigma_{v}\right)$ & $\left(w_{2}, \sigma_{v}\right)$ \\
\hline \multirow[t]{4}{*}{ Sand } & \multirow[t]{2}{*}{33} & Normal & -0.94 & +0.10 & -0.19 \\
\hline & & Oblique & -0.64 & +0.55 & -0.45 \\
\hline & \multirow[t]{2}{*}{93} & Normal & -0.87 & -0.32 & +0.64 \\
\hline & & Oblique & -0.85 & +0.90 & -0.88 \\
\hline \multirow[t]{4}{*}{ Silt } & \multirow[t]{2}{*}{33} & Normal & -0.30 & -0.31 & +0.02 \\
\hline & & Oblique & -0.47 & -0.44 & +0.32 \\
\hline & \multirow[t]{2}{*}{93} & Normal & -0.86 & -0.28 & +0.12 \\
\hline & & Oblique & +0.42 & -0.23 & -0.14 \\
\hline \multirow[t]{4}{*}{ Clay } & \multirow[t]{2}{*}{33} & Normal & +0.05 & -0.75 & +0.04 \\
\hline & & Oblique & +0.44 & +0.07 & -0.05 \\
\hline & \multirow[t]{2}{*}{93} & Normal & -0.62 & -0.66 & +0.57 \\
\hline & & Oblique & +0.26 & -0.24 & -0.29 \\
\hline
\end{tabular}

procedure, $\left(M_{\phi}, w_{2}, \sigma_{v}\right)$ solutions close to the mean value for each (substrate, frequency, orientation) combination were chosen. Then, for each original solution, 20 synthetic average echo envelopes and matched parameter solutions were generated as described in Sec. III C.

For each measurement scenario, an original solution and the mean and standard deviation of the corresponding Monte Carlo solution are summarized in Table II. Correlation between parameter pairs are summarized in Table III. The Monte Carlo solutions for $w_{2}$ vs $M_{\phi}$ are shown in Figs. 13 and 14 for 33 and $93 \mathrm{kHz}$, respectively. The distributions of Monte Carlo solutions are adequately represented by the confidence regions - with the exception of Fig. 13(b) (sand, $33 \mathrm{kHz}$, oblique) which demonstrates one-sided $w_{2}$ clustering about 0.0055 . The mean values of the Monte Carlo solutions are in general agreement with the original solutions, with the exception of Fig. 14(d) (silt, $93 \mathrm{kHz}$, oblique).
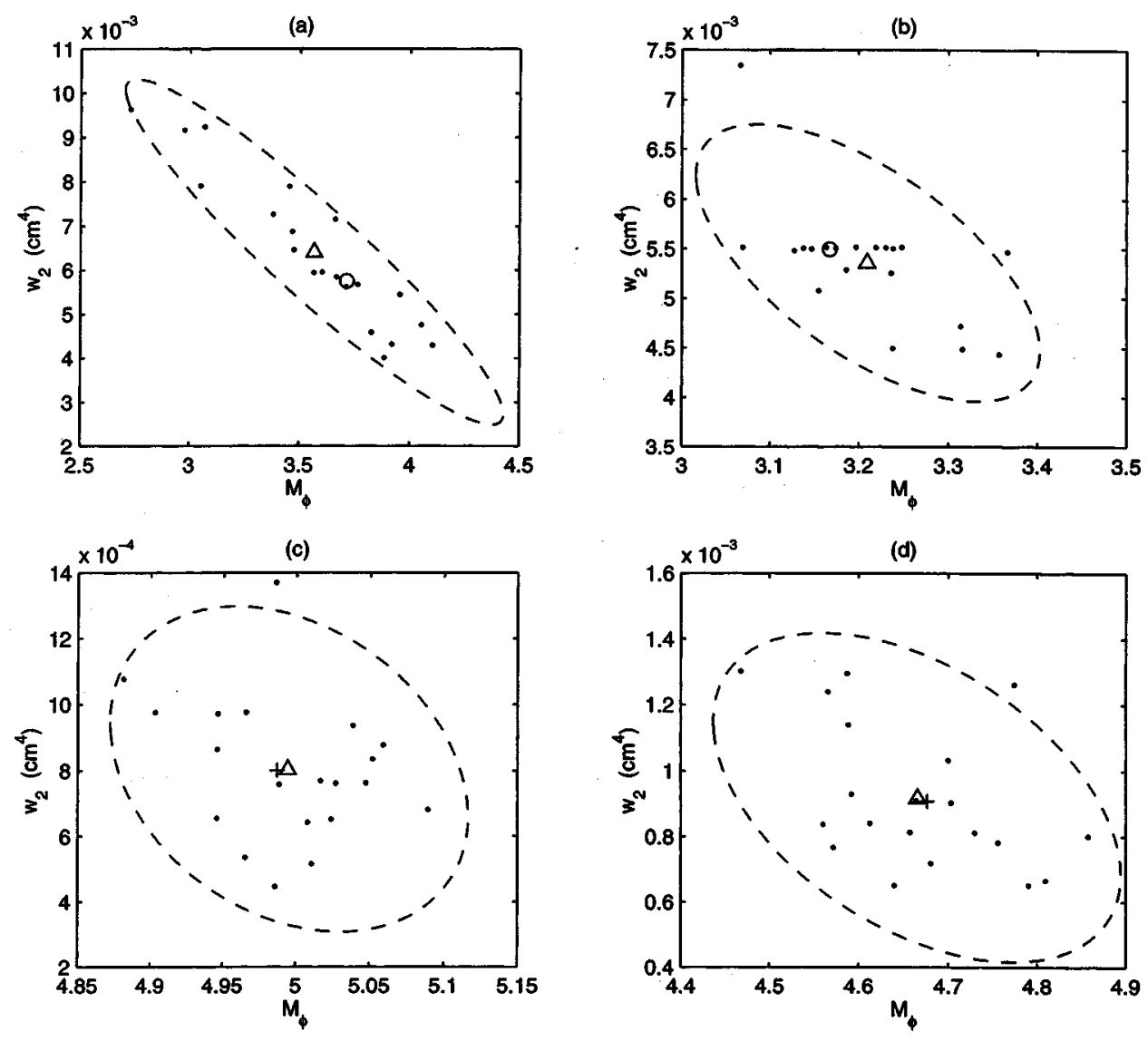

FIG. 13. Scatter plot of Monte Carlo solutions at $33 \mathrm{kHz}$ : Panel descriptions in Table II. $(\cdot)$ Monte Carlo solutions; $(\triangle)$ mean value and center of $90 \%$ confidence region; $(\bigcirc)$ original sand solution; (+) original silt solution; (*) original clay solution.
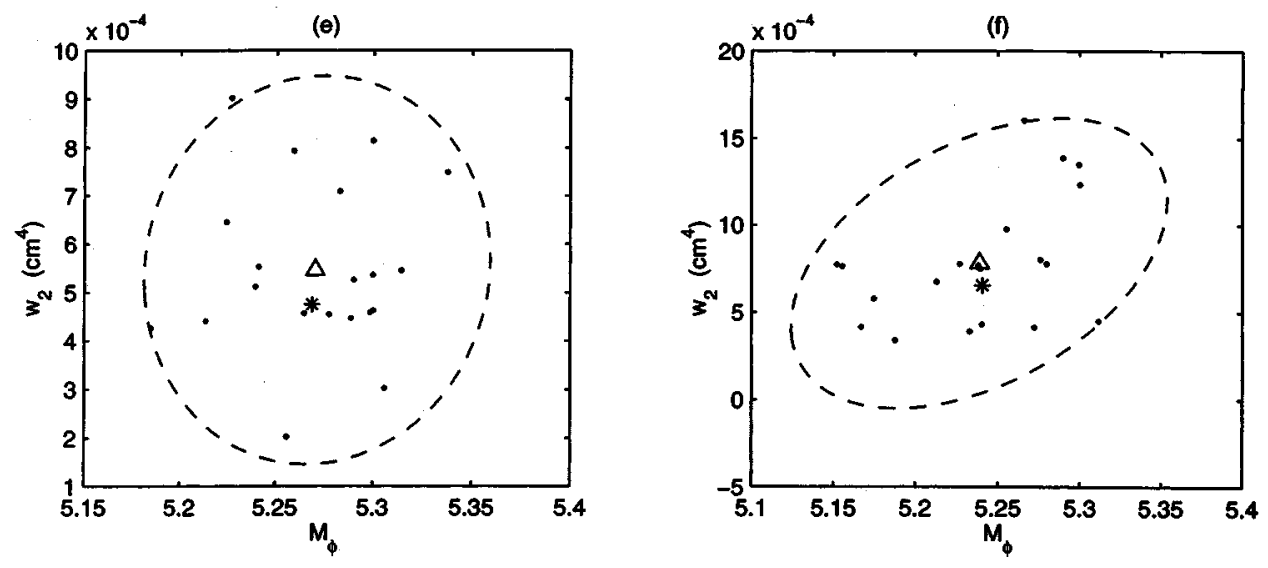

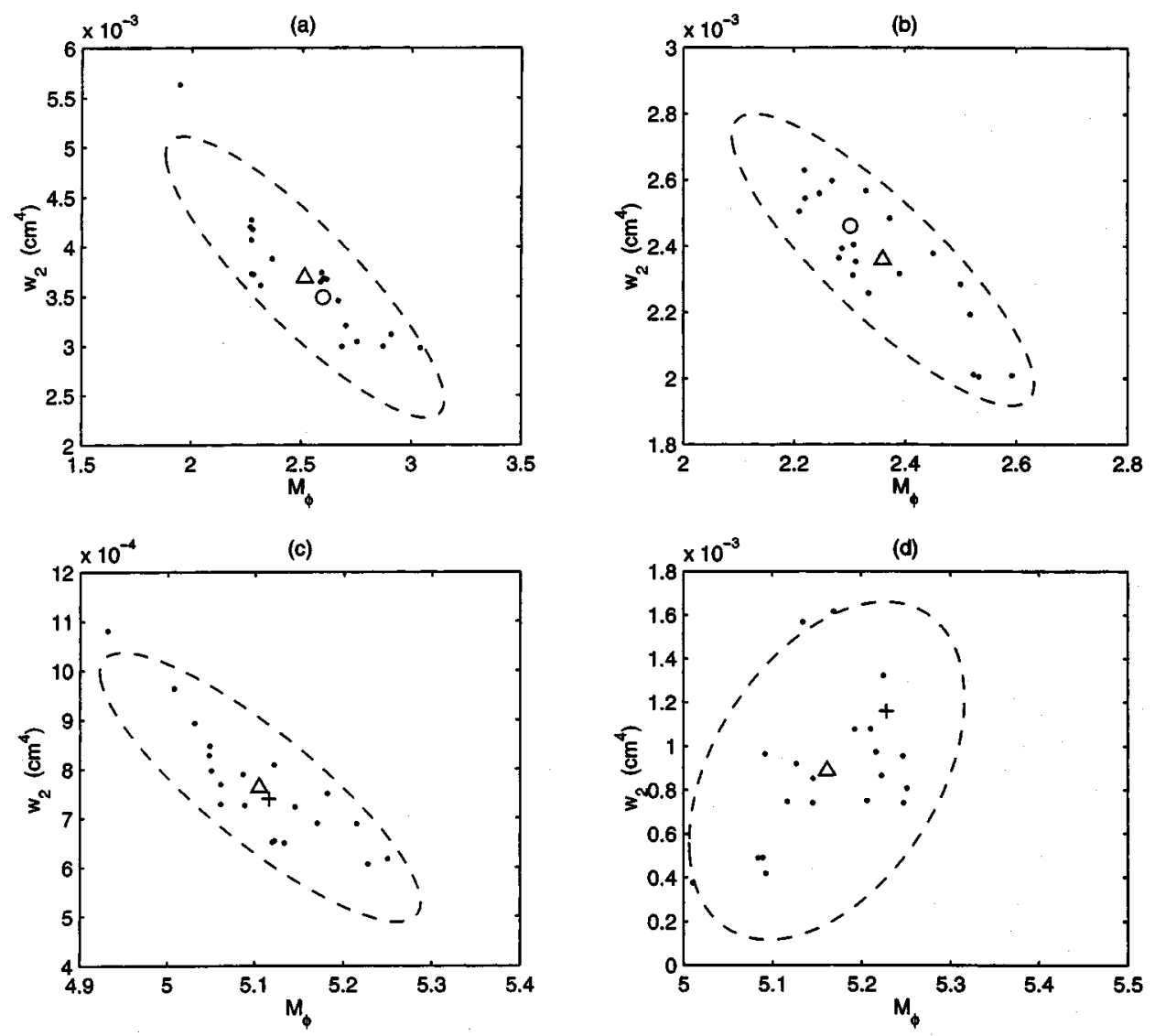

FIG. 14. Scatter plot of Monte Carlo solutions at $93 \mathrm{kHz}$ : Panel descriptions in Table II. (.) Monte Carlo solutions; $(\triangle)$ mean value and center of $90 \%$ confidence region; $(\bigcirc)$ original sand solution; $(+)$ original silt solution; $(*)$ original clay solution.

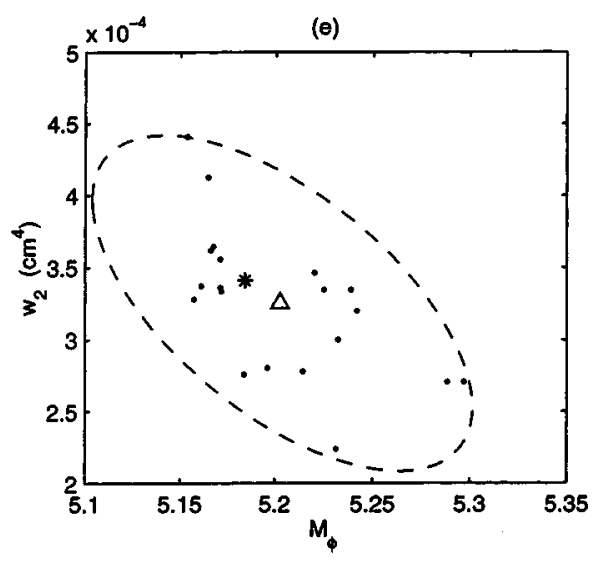

In Figs. 15 and 16, 90\%-confidence regions for the Monte Carlo solutions are juxtaposed with those for the model-data solutions reported in Sec. V (henceforth called the "real" solutions) at 33 and $93 \mathrm{kHz}$, respectively. In general, the confidence regions of the Monte Carlo solutions fall within those of the real solutions. However, the plots suggest that for normal incidence over sand at $33 \mathrm{kHz}$, variations in $M_{\phi}$ and $w_{2}$ are larger than suggested by the limited number of field measurements. The same can be said of $w_{2}$ estimates for oblique incidence over clay at $33 \mathrm{kHz}$. This implies that analysis of larger data sets could yield greater solution variability than what is currently observed.

As observed for the real solutions, the Monte Carlo estimates of $M_{\phi}$ for sand exhibit greater variability than for fines - with measures of standard deviation ranging from 0.08 to 0.38 and 0.04 to 0.10 , respectively. As a percentage of the mean value, $w_{2}$ standard deviations for fine-grain simulations $(15 \%-46 \%)$ are typically larger than those for sand $(8 \%-27 \%)$. Standard deviations for $\sigma_{v}$ are typically less than $10 \%$ of the mean value, with exceptions for sand at $33 \mathrm{kHz}$.

Also, a significant anticorrelation between $M_{\phi}$ and $w_{2}$ for sand substrates is seen in the real solutions and in the Monte Carlo solutions, with correlation coefficients ranging from -0.64 to -0.94 . In the temporal model of acoustic backscatter, increasing either parameter decreases signal peak amplitude, and vice versa. In nature, these quantities are expected to be negatively correlated-i.e., coarser sediments (lower $M_{\phi}$ ) exhibit more energy in the relief energy density spectrum (larger $w_{2}$ ). When the "true" signal is contaminated by "noise" the parameters also tend to adjust in opposite directions.

There also appears to be modest anticorrelation between $M_{\phi}$ and $\sigma_{v}$ in solutions for fine-grain sediments. In these substrates, scattering from the sediment volume typically plays a larger role. An increase in either parameter raises the 

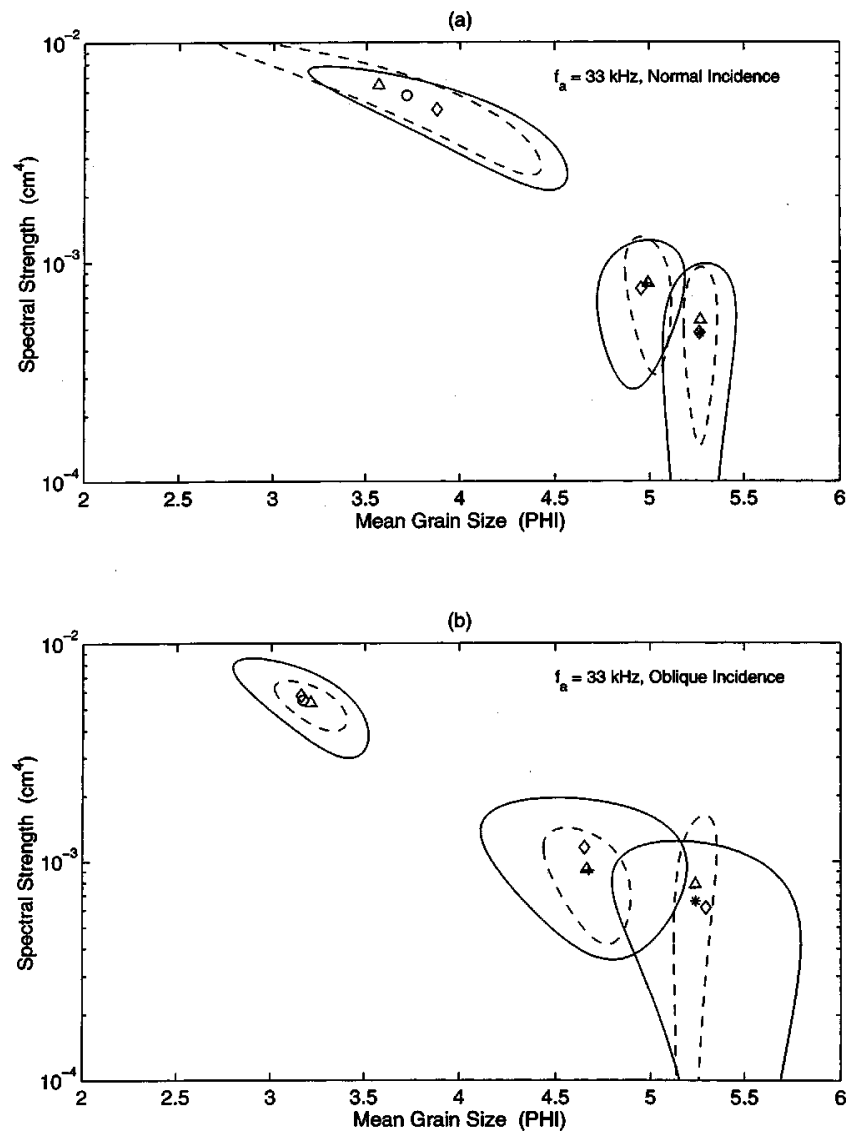

FIG. 15. Confidence regions for Monte Carlo and real solutions $(33 \mathrm{kHz})$. Real solutions: Solid lines — ues. Monte Carlo solutions: Dashed lines $---90 \%$-confidence regions; $(\triangle)$ mean values; $(\bigcirc)$ original sand solution; $(+)$ original silt solution; $(*)$ original clay solution. Transducer orientation: (a) Normal; (b) Oblique.

calculated energy in the signal tail, and apparently the two parameters compete to fit this section of the signal. Too little is known about in situ sediment volume scattering characteristics to warrant a physical interpretation.

In theory, values of the data covariance matrix (and thus the solution variance) can be decreased by averaging a larger number of echoes. However, in our data sets, processing ensembles much greater than 100 pings excessively filters the shape characteristics of the average envelope that are essential to the matching procedure. Furthermore, with large ensembles the requirement of bottom homogeneity is more likely to be violated-especially at high survey speeds.

In theory also, the data covariance matrix has potential application in model-data fitting. The nonweighted leastsquares merit function of Eq. (5) was chosen over a varianceweighted approach in order to favor peak amplitude modeldata matching - emphasizing extraction of mean grain size correlated parameters, such as impedance contrast. Future work with this technique will include testing of the full maximum likelihood estimation (MLE) paradigm; i.e., covariance matrix weighting of the model-data disparity. Variance weighting of each model-data sample disparity should improve model-data fitting at the leading and trailing signal edges - at the expense of precise peak amplitude matching. The effect, however, of the data's covariances should coerce the optimized model to assume the true "shape" of the mea- sured envelope. Comparisons between full MLE optimization and peak amplitude (nonweighted) matching will be evaluated in future evolutions of this echo envelope sediment characterization algorithm.

\section{SUMMARY}

The method for estimating sediment geoacoustic parameters presented here compares bottom returns measured by a calibrated, moderate beamwidth $\left(10^{\circ}-21^{\circ}\right)$, vertically oriented $\left(0^{\circ}-15^{\circ}\right)$ monostatic sonar, with an echo envelope model based on high-frequency $(10-100 \mathrm{kHz})$ incoherent backscatter theory and sediment properties such as mean grain size $\left(M_{\phi}\right)$, interface roughness $\left(w_{2}, \gamma\right)$, and sediment volume scattering statistics $\left(\sigma_{v}\right)$. A two-stage average echo envelope matching procedure was described where: first, the sediment type (sand or fines) is established by iterating on the reflection coefficient to match the peak echo amplitude, and to establish a general fit with generic values of the remaining geoacoustic parameters; then, a three-parameter global optimization is performed using a combination of simulated annealing and downhill simplex searches over the allowable range of interface roughness spectral strength, sediment volume scattering coefficient, and a constrained range of reflection and bottom absorption coefficients correlated to mean grain size. In San Diego Bay, bottom echoes were collected at 33 and $93 \mathrm{kHz}$ over substrates ranging from sand to clay. Application of the sediment characterization method to these data yielded solutions for grain size and geoacoustic properties that are consistent with ground-truth measurements.

The ground-truth measurements, consisting of bottom video, grain size analyses, environmental databases, and associated ranges of geoacoustic parameters, lack direct assessments of the modeled geoacoustic properties. This, and the small number of sites and regions evaluated, limits definitive assessment of the accuracy and robustness of the described inversion technique. Controlled, calibrated surveys over sites characterized for the complete range of geoacoustic parameters must eventually be employed to further evaluate and improve the efficacy of the echo envelope sediment characterization technique.

For the experiments described in this paper, analyses of the estimated geoacoustic parameters for different combinations of sediment type, frequency, and transducer orientation suggest that moderate frequencies $(33 \mathrm{kHz})$ and normal incidence are more suitable for this method of sediment characterization. This may, in part, be due to limitations at high acoustic frequencies (e.g., $93 \mathrm{kHz}$ ) of the backscatter model's underlying Kirchhoff theory, and partly due to the simple temporal structure of the returns at lower acoustic frequencies $(33 \mathrm{kHz})$ - simplifying calculation of the average echo envelope. Furthermore, approximate alignment of the transducer's maximum response axis at normal incidence insures that the maximum interface component of the backscattered signal will exceed the maximum volume contribution-a condition necessary for reducing ambiguity in the modeldata matching procedure.

The ability to distinguish sands from fine-grain sediments was demonstrated based on acoustic estimation of 
(a)
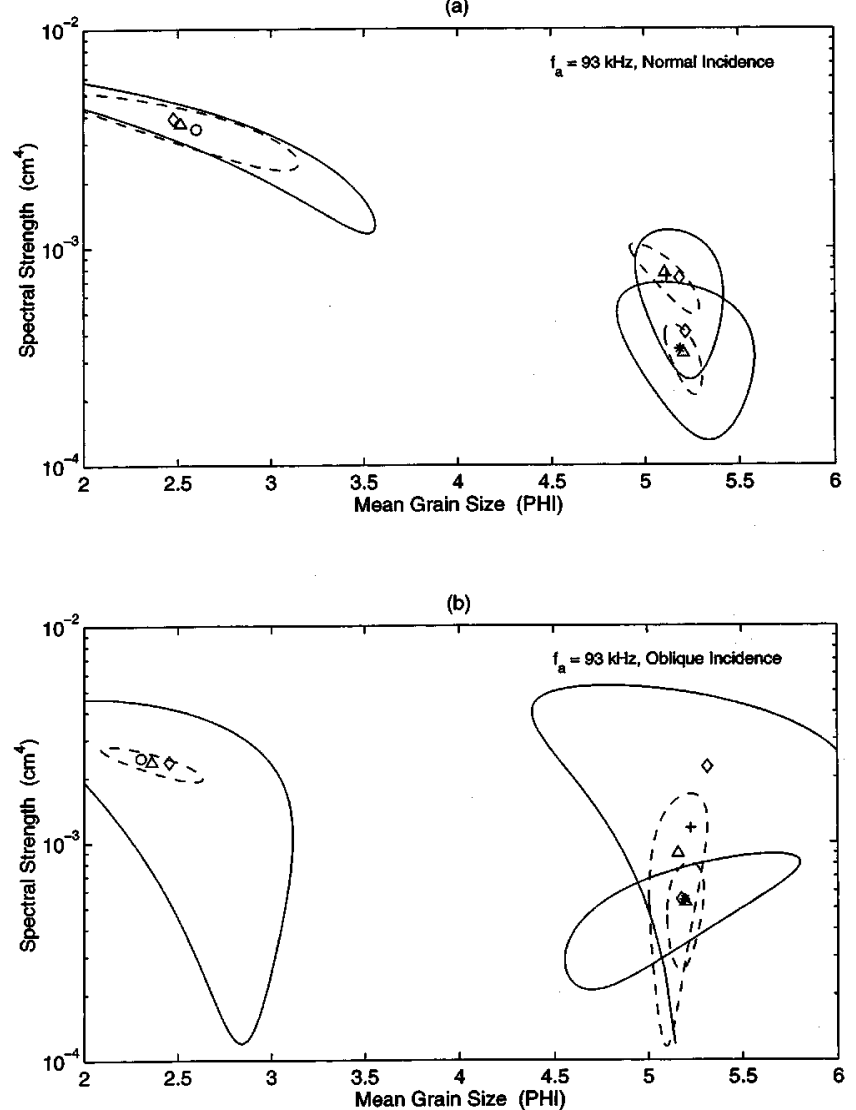

FIG. 16. Confidence regions for Monte Carlo and real solutions $(93 \mathrm{kHz})$. Real solutions: Solid lines — ues. Monte Carlo solutions: Dashed lines - - $-90 \%$-confidence regions; $(\triangle)$ mean values; $(\bigcirc)$ original sand solution; $(+)$ original silt solution; $(*)$ original clay solution. Transducer orientation: (a) Normal; (b) Oblique.

mean grain size alone. The creation of feature vectors from estimates of mean grain size $\left(M_{\phi}\right)$ and interface roughness spectral strength $\left(w_{2}\right)$ showed promise for intraclass separation of silt and clay. Limitations on interface curvature dictated by the Kirchhoff approximation restrict application of this scheme to sediments having a large rms radius of curvature relative to the acoustic wavelength. This excludes extremely rough (rocky) substrates, or operation at high fre- quencies $(>100 \mathrm{kHz})$. Furthermore, local deviations of sediment:water impedance ratio $(\rho \nu)$ and sediment acoustic attenuation constant $\left(\kappa_{p}\right)$ from generic values (mean values correlated with $M_{\phi}$ ) will result in estimates of $M_{\phi}, w_{2}$, and $\sigma_{v}$ that are distorted from their true values.

Monte Carlo simulations based on a geoacoustic parameter solution set and the data's covariance matrix were described. In the mean, the Monte Carlo solutions agree with the original solution; however, for a given substrate, there is as much variability in the Monte Carlo solutions as there are in an ensemble of real solutions. Therefore, echo variability must be considered during parameter optimization by providing confidence limits on the results.

According to the observed spread of geoacoustic matches from measured signals and synthetic data, roughness spectral strength estimates $\left(w_{2}\right)$ for sand substrates are relatively immune to raw echo variability, whereas mean grain size estimates $\left(M_{\phi}\right)$ are moderately affected. The opposite is observed for fine-grain substrates: $M_{\phi}$ estimates are relatively immune to raw echo variability, whereas $w_{2}$ estimates are significantly affected. A more thorough investigation of echo envelope averaging procedures and maximum likelihood model-data matching techniques may result in methods to reduce the $\left(M_{\phi}, w_{2}\right)$ confidence regions.

Finally, the classification procedure introduces a degree of anticorrelation between $M_{\phi}$ and $w_{2}$, which is especially large for sand substrates. This trend is consistent with what is expected in nature, where the relief energy density spectra of coarser sediments (lower $M_{\phi}$ ) exhibit more energy (higher $W_{2}$ ) than those of fine-grain substrates.

\section{ACKNOWLEDGMENTS}

We are grateful to the Space and Naval Warfare Systems Center (SPAWAR) for their assistance in collecting acoustic data and bottom samples, Reson Inc. for the generous loan of sonar transducers, and ORINCON Defense for their professional support. We thank Professor William Coles for his input on conducting the error analysis, and Jo Griffith for her help in preparing the illustrations. This work was funded by the Office of Naval Research under Contract No. N0001494-1-0121.

\section{APPENDIX: SUPPORTING TABLES}

TABLE IV. Survey site ground truth. Substrate percentages may not add exactly to 100 due to round-off and a small gravel constituency.

\begin{tabular}{ccccccccc}
\hline \hline Site & $\begin{array}{c}\text { Sample } \\
\text { index }\end{array}$ & $\begin{array}{c}\text { Latitude } \\
\text { deg min } \\
\text { North }\end{array}$ & $\begin{array}{c}\text { Longitude } \\
\text { deg min } \\
\text { West }\end{array}$ & $\begin{array}{c}\text { Mean grain } \\
\text { size (PHI) }\end{array}$ & $\begin{array}{c}\text { Mean grain } \\
\text { size }(\mu \mathrm{m})\end{array}$ & $\begin{array}{c}\% \\
\text { Sand }\end{array}$ & $\begin{array}{c}\% \\
\text { Silt }\end{array}$ & $\begin{array}{c}\% \\
\text { Clay }\end{array}$ \\
\hline Sand & 1 & 3240.760 & 11713.653 & 1.9 & 268 & 93 & 2 & 4 \\
& 2 & 3240.650 & 11713.585 & 2.2 & 218 & 93 & 2 & 4 \\
& 3 & 3240.647 & 11713.626 & 1.7 & 308 & 90 & 3 & 4 \\
Silt & 1 & 3242.265 & 11713.927 & 4.1 & 58 & 76 & 14 & 10 \\
& 2 & 3241.887 & 11714.153 & 5.9 & 17 & 49 & 30 & 21 \\
& & & & & & & & \\
Clay & 1 & 3242.997 & 11711.728 & 6.5 & 11 & 39 & 33 & 27 \\
& 2 & 3242.995 & 11711.767 & 6.8 & 9 & 36 & 34 & 29 \\
& 3 & 3242.997 & 11711.814 & 6.6 & 10 & 38 & 33 & 29 \\
\hline \hline
\end{tabular}


TABLE V. Survey measurement characteristics. Normal incidence measurements refer to those for which the central axis of the transducer's radiation pattern is aligned with the bottom normal (mean $\theta_{T} \sim 0$ ). Oblique incidence measurements exhibit elevation angles roughly corresponding to $\theta_{3 d B} / 2\left(8^{\circ}-12^{\circ}\right.$ and $6^{\circ}-9^{\circ}$, respectively, at 33 and $93 \mathrm{kHz}$ ). Columns 3-6 represent mean or approximate values.

\begin{tabular}{|c|c|c|c|c|c|c|c|c|}
\hline Site & Freq $(\mathrm{kHz})$ & $\begin{array}{l}\text { Transducer } \\
\text { orientation }\end{array}$ & $\begin{array}{l}\text { Transducer } \\
\text { elevation } \\
\text { angle } \\
\theta_{T}(\mathrm{deg})\end{array}$ & $\begin{array}{l}\text { Transducer } \\
\text { altitude } \\
\text { alt }(\mathrm{m})\end{array}$ & $\begin{array}{l}\text { Along-track } \\
\text { 3-dB } \\
\text { footprint } \\
D_{3}(\mathrm{~m})\end{array}$ & $\begin{array}{l}\text { Along-track } \\
\text { 6-dB } \\
\text { footprint } \\
D_{6}(\mathrm{~m})\end{array}$ & $\begin{array}{l}\text { Transmission } \\
\text { source level } \\
\mathrm{dB} \text { re: } 1 \mu \mathrm{Pa} \\
\text { @ } 1 \mathrm{~m}\end{array}$ & $\begin{array}{c}\text { Figure } \\
\text { label }\end{array}$ \\
\hline \multirow{4}{*}{$\overline{\text { Sand }}$} & \multirow[t]{2}{*}{33} & Normal & 2.0 & 13.5 & 5.0 & 7.0 & 197.8 & 9 (a) \\
\hline & & Oblique & 12.0 & 13.5 & 5.0 & 7.0 & 197.8 & 9 (b) \\
\hline & \multirow[t]{2}{*}{93} & Normal & 2.0 & 13.5 & 2.4 & 3.1 & 191.4 & 10 (a) \\
\hline & & Oblique & 6.5 & 14 & 2.5 & 3.2 & 191.4 & $10(b)$ \\
\hline \multirow[t]{4}{*}{ Silt } & \multirow[t]{2}{*}{33} & Normal & 2.0 & 16 & 5.9 & 8.3 & 192.4 & $9(\mathrm{c})$ \\
\hline & & Oblique & 8.0 & 16.5 & 6.1 & 8.5 & 192.4 & $9(\mathrm{~d})$ \\
\hline & \multirow[t]{2}{*}{93} & Normal & 2.0 & 19 & 3.3 & 4.3 & 192.3 & $10(c)$ \\
\hline & & Oblique & 8.5 & 19 & 3.3 & 4.3 & 192.3 & $10(d)$ \\
\hline \multirow[t]{4}{*}{ Clay } & \multirow[t]{2}{*}{33} & Normal & 0 & 12 & 4.5 & 6.2 & 197.8 & $9(\mathrm{e})$ \\
\hline & & Oblique & 12.0 & 11 & 4.1 & 5.7 & 197.8 & $9(\mathrm{f})$ \\
\hline & \multirow[t]{2}{*}{93} & Normal & 1.0 & 12.5 & 2.2 & 2.8 & 191.4 & $10(\mathrm{e})$ \\
\hline & & Oblique & 7.0 & 13 & 2.3 & 3.0 & 191.4 & $10(\mathrm{f})$ \\
\hline
\end{tabular}

TABLE VI. Sediment classification statistics.

\begin{tabular}{|c|c|c|c|c|c|c|c|c|c|}
\hline Site & Freq $(\mathrm{kHz})$ & $\begin{array}{l}\text { Transducer } \\
\text { orientation }\end{array}$ & $\begin{array}{c}\text { Mean } \\
M_{\phi}\end{array}$ & $\begin{array}{l}\text { Stdv } \\
M_{\phi}\end{array}$ & $\gamma$ & $\begin{array}{c}\text { Mean } w_{2} \\
\left(\mathrm{~cm}^{4}\right)\end{array}$ & $\begin{array}{c}\operatorname{Stdv} w_{2} \\
\left(\mathrm{~cm}^{4}\right)\end{array}$ & $\underset{\left(\mathrm{m}^{-1}\right)}{\operatorname{Mean} \sigma_{v}}$ & $\begin{array}{c}\operatorname{Stdv} \sigma_{v} \\
\left(\mathrm{~m}^{-1}\right)\end{array}$ \\
\hline \multirow[t]{4}{*}{ Sand } & \multirow[t]{2}{*}{33} & Normal & 3.88 & 0.28 & 3.00 & 0.00496 & 0.00113 & 0.202 & 0.022 \\
\hline & & Oblique & 3.16 & 0.14 & 3.00 & 0.00577 & 0.00109 & 0.041 & 0.020 \\
\hline & \multirow[t]{2}{*}{93} & Normal & 2.48 & 0.44 & 3.00 & 0.00391 & 0.00110 & 0.945 & 0.343 \\
\hline & & Oblique & 2.45 & 0.27 & 3.00 & 0.00236 & 0.00090 & 0.104 & 0.112 \\
\hline \multirow[t]{4}{*}{ Silt } & \multirow[t]{2}{*}{33} & Normal & 4.96 & 0.09 & 3.30 & 0.00076 & 0.00020 & 0.071 & 0.010 \\
\hline & & Oblique & 4.65 & 0.22 & 3.30 & 0.00115 & 0.00032 & 0.091 & 0.016 \\
\hline & \multirow[t]{2}{*}{93} & Normal & 5.18 & 0.09 & 3.30 & 0.00072 & 0.00019 & 0.261 & 0.070 \\
\hline & & Oblique & 5.32 & 0.38 & 3.30 & 0.00223 & 0.00124 & 0.314 & 0.227 \\
\hline \multirow[t]{4}{*}{ Clay } & \multirow[t]{2}{*}{33} & Normal & 5.26 & 0.08 & 3.30 & 0.00048 & 0.00021 & 0.048 & 0.022 \\
\hline & & Oblique & 5.30 & 0.20 & 3.30 & 0.00061 & 0.00024 & 0.047 & 0.015 \\
\hline & \multirow[t]{2}{*}{93} & Normal & 5.21 & 0.15 & 3.30 & 0.00041 & 0.00011 & 0.102 & 0.040 \\
\hline & & Oblique & 5.18 & 0.24 & 3.30 & 0.00055 & 0.00013 & 0.170 & 0.053 \\
\hline
\end{tabular}

TABLE VII. Sediment classification: Parameter correlation.

\begin{tabular}{cccccc}
\hline \hline \multirow{2}{*}{ Site } & Freq. $(\mathrm{kHz})$ & $\begin{array}{c}\text { Transducer } \\
\text { orientation }\end{array}$ & $\left(M_{\phi}, w_{2}\right)$ & $\left(M_{\phi}, \sigma_{v}\right)$ & $\left(w_{2}, \sigma_{v}\right)$ \\
\hline Sand & 33 & Normal & -0.86 & -0.79 & +0.37 \\
& & Oblique & -0.72 & -0.78 & -0.48 \\
& \multirow{2}{*}{93} & Normal & -0.96 & -0.79 & +0.77 \\
& & Oblique & -0.58 & +0.66 & +0.07 \\
& & & & & \\
Silt & 33 & Normal & +0.19 & +0.07 & -0.6 \\
& \multirow{2}{*}{93} & Oblique & -0.27 & +0.17 & -0.74 \\
& & Normal & -0.23 & -0.87 & +0.44 \\
& & Oblique & -0.58 & -0.07 & +0.60 \\
& & & & & \\
Clay & 33 & Normal & +0.18 & -0.50 & -0.11 \\
& & Oblique & -0.31 & -0.64 & -0.2 \\
& 93 & Normal & -0.34 & -0.77 & +0.17 \\
& & Oblique & +0.77 & +0.26 & +0.07 \\
\hline \hline
\end{tabular}

${ }^{1}$ N. G. Pace and R. V. Ceen, "Seabed classification using the backscattering of normally incident broadband acoustic pulses," Hydrographic J. 26, 9-16 (1982)

${ }^{2}$ R. Chivers, N. Emerson, and D. R. Burns, "New acoustic processing for underway surveying," Hydrographic J. 56, 9-17 (1990).

${ }^{3}$ L. A. Mayer. UNB-OMG/UNH-CCOM Multibeam Sonar Traning Course Notes, November 2002.

${ }^{4}$ A. S. Tsehmahman, W. T. Collins, and B. T. Prager, "Acoustic seabed classification and correlation analysis of sediment properties by QTC view," in Proceedings of IEEE OCEANS 97, pp. 921-926, 1997.

${ }^{5}$ G. J. Heald and N. G. Pace, "An analysis of 1st and 2nd backscatter for seabed classification," in Proceedings of III European Conference on Underwater Acoustics, Crete, June 1996, pp. 649-654.

${ }^{6}$ G. J. Heald and N. G. Pace, "Implications of bi-static treatment for the second echo from a normal incidence sonar," in Proceedings: 16th International Congress on Acoustics and 135th Meeting Acoustical Society of America, Seattle, Washington, June 1998, Vol. IV, pp. 30093010.

${ }^{7}$ S. G. Schock, L. R. LeBlanc, and L. A. Mayer, "Chirp subbottom profiler for quantitative sediment analysis," Geophysics 54(4), 445-450 (1989). 
${ }^{8}$ L. R. LeBlanc, L. Mayer, M. Rufino, and J. King, "Marine sediment classification using the chirp sonar," J. Acoust. Soc. Am. 91(1), 107-115 (1991).

${ }^{9}$ M. V. Berry, "The statistical properties of echoes diffracted from rough surfaces," Philos. Trans. R. Soc. London, Ser. A 273, 611-654 (1973).

${ }^{10}$ E. H. Nesbitt, "Estimation of sea bottom parameters using acoustic backscattering at vertical incidence," Master's thesis, University of Washington, 1988.

${ }^{11}$ D. R. Jackson and E. Nesbitt, "Bottom classification using backscattering at vertical incidence," J. Acoust. Soc. Am. Suppl. 1 83, S80 (1988).

${ }^{12} \mathrm{X}$. Lurton and E. Pouliquen, "Identification de la nature du fond de la mer à l'aide de signaux d'écho-sondeurs. II. Méthode d'identification et résulatats experimentaux," Acta Acust. (European Acoustics Association) 2(3), 187-194 (1994).

${ }^{13}$ D. D. Sternlicht and C. P. de Moustier, "Time-dependent seafloor acoustic backscatter (10-100 kHz)," J. Acoust. Soc. Am. 114, 2709-2725 (2003).

${ }^{14}$ D. R. Jackson, D. P. Winebrenner, and A. Ishimaru, "Application of the composite roughness model to high-frequency bottom backscattering," J. Acoust. Soc. Am. 79(5), 1410-1422 (1986).

${ }^{15} \mathrm{C}$. K. Wentworth, "A scale of grade and class terms for clastic sediments," J. Geol. 30(5), 377-392 (1922).

${ }^{16}$ W. C. Krumbein, "Application of logarithmic moments to size frequency distribution of sediments," J. Sediment. Petrol. 6, 35-47 (1936).

${ }^{17}$ Applied Physics Laboratory. High-Frequency Ocean Environmental Acoustic Models Handbook. Technical report, APL-UW TR9407, AEAS 9501 University of Washington, 1994.

${ }^{18}$ E. L. Hamilton, "Compressional wave attenuation in marine sediments," Geophysics 37, 620-646 (1972).

${ }^{19}$ Z. H. Michalopoulou, D. Alexandrou, and C. de Moustier, "Application of a maximum likelihood processor to acoustic backscatter for the estimation of seafloor roughness parameters," J. Acoust. Soc. Am. 95(5), 2467-2477 (1994).

${ }^{20}$ H. Matsumoto, R. P. Dziak, and C. Fox, "Estimation of seafloor microtopographic roughness through modeling of acoustic backscatter data recorded by multi-beam systems," J. Acoust. Soc. Am. 94(5), 2776-2787 (1993).

${ }^{21}$ D. D. Sternlicht and C. P. de Moustier, "Temporal modeling of high frequency $(30-100 \mathrm{kHz})$ acoustic seafloor backscatter: Shallow water results," in High Frequency Acoustics in Shallow Water, CP-45, pp. 509-516, Lerici, Italy, July 1997. NATO SACLANT Undersea Research Centre.

${ }^{22}$ G. E. Forsythe, M. A. Moler, and B. Cleve, Computer Methods for Mathematical Computations (Prentice-Hall, Englewood Cliffs, NJ, 1977).

${ }^{23}$ S. Kirkpatrick, C. D. Gelatt, Jr., and M. P. Vecchi, "Optimization by simulated annealing," Science 220(4598), 671-680 (1983).

${ }^{24}$ M. Metropolis, A. Rosenbluth, M. Rosenbluth, A. Teller, and E. E. Teller, "Equations of state calculations by fast computing machines," J. Chem. Phys. 21, 1087-1091 (1953).

${ }^{25}$ W. H. Press and S. A. Teukolsky, "Simulated annealing optimization over continuous spaces," Comput. Phys. 5, 426-429 (1991).

${ }^{26}$ S. Geman and D. Geman, "Stochastic relaxation, Gibbs distributions, and the Bayesian restoration of images," IEEE Trans. Pattern Anal. Mach. Intell. 6, 721-741 (1984).

${ }^{27}$ D. D. Sternlicht, "High Frequency Acoustic Remote Sensing of Seafloor Characteristics," Ph.D. thesis, Univeristy of California, San Diego, 1999.

${ }^{28}$ R. H. Plumb, "Procedure for handling and chemical analysis of sediment and water samples," Technical Report TR-EPA/CE-81-1, U.S. Army Engineer Waterways Experiment Station, Vicksburg, Mississippi, 1981.

${ }^{29}$ P. D. Mourad and D. R. Jackson, "High frequency sonar equation models for bottom backscattering and forward loss," in Proceedings of IEEE OCEANS 89, pp. 1168-1175, 1989.

${ }^{30}$ A. P. Lyons and T. H. Orsi, "The effect of a layer of varying density on high-frequency reflection, forward loss, and backscatter," IEEE J. Ocean. Eng. 23(4), 411-422 (1998).

${ }^{31}$ S. Stanic, K. B. Briggs, P. Fleischer, W. B. Sawyer, and R. I. Ray, "Highfrequency acoustic backscattering," J. Acoust. Soc. Am. 85(1), 125-136 (1989).

${ }^{32}$ D. R. Jackson, J. J. Crisp, and P. A. Thompson, "High-frequency bottom backscatter measurements in shallow water," J. Acoust. Soc. Am. 80(4), 1188-1199 (1986)

${ }^{33}$ D. R. Jackson and K. B. Briggs, "High-frequency bottom backscattering: Roughness versus sediment volume scattering," J. Acoust. Soc. Am. 92(2), 962-977 (1992). 